Pontifícia Universidade Católica $_{\text {mato }}$

Breno Maurício Mattos Martins

Decomposição da Curva de Juros Brasileira

Dissertação apresentada como requisito parcial para obtenção do grau de Mestre pelo Programa de Pós-graduação em Macroeconomia e Finanças do Departamento de Economia do Centro de Ciências Sociais da PUC-Rio.

Orientador: Prof. Márcio Gomes Pinto Garcia 


\title{
Decomposição da Curva de Juros Brasileira
}

Dissertação apresentada como requisito parcial para obtenção do grau de Mestre pelo Programa de Pós-graduação em Macroeconomia e Finanças do Departamento de Economia do Centro de Ciências Sociais da PUC-Rio. Aprovada pela Comissão Examinadora abaixo:

\author{
Prof. Márcio Gomes Pinto Garcia \\ Orientador \\ Departamento de Economia - PUC-Rio
}

Prof. Walter Novaes Filho

Departamento de Economia - PUC-Rio

Prof. Pablo Hector Seuanez Salgado

Bahia Asset Management

Rio de Janeiro, 16 de Novembro de 2020 
Todos os direitos reservados. É proibida a reprodução total ou parcial do trabalho sem autorização da universidade, do autor e do orientador.

\section{Breno Maurício Mattos Martins}

Graduou-se em Ciências Econômicas pela Universidade Federal Fluminense (UFF).

Ficha Catalográfica

Mattos Martins, Breno Maurício

Decomposição da Curva de Juros Brasileira / Breno Maurício Mattos Martins; orientador: Márcio Gomes Pinto Garcia. - Rio de janeiro: PUC-Rio, Departamento de Economia , 2020.

v., 52 f: il. color. ; $30 \mathrm{~cm}$

Dissertação (mestrado) - Pontifícia Universidade Católica do Rio de Janeiro, Departamento de Economia .

Inclui bibliografia

1. Economia - Teses.

2. Prêmio de Risco;. 3. Expectativa;. 4. Curva de Juros;. 5. Modelo Gaussiano Afim;.

I. Gomes Pinto Garcia, Márcio. II. Pontifícia Universidade Católica do Rio de Janeiro. Departamento de Economia . III. Título.

CDD: 330 


\section{Agradecimentos}

Agradeço à Caroline Martins, minha esposa, por toda paciência, apoio e carinho durante este período e nos últimos 7 anos.

Aos meus pais, Ana Lúcia e Sérgio Martins, por todo amor e apoio incondicional.

Aos meus irmãos, Bruno Martins e Bernardo Martins, por sempre terem sido os meus melhores amigos.

À minha avó, Rodmar Peçanha de Mattos, e minha dinda, Elizabeth Rose Costa Martins, por todo amor e ensinamentos.

Ao professor e orientador, Márcio Garcia, pelo suporte durante este trabalho e por todo aprendizado.

À MAG Investimentos, pelo suporte financeiro e apoio nos estudos.

Ao amigo, Julio Barros, por toda ajuda ao longo do mestrado.

Aos meus colegas de classe, ao corpo docente da PUC-Rio e aos funcionários, meu muito obrigado. 


\section{Resumo}

Mattos Martins, Breno Maurício; Gomes Pinto Garcia, Márcio. Decomposição da Curva de Juros Brasileira. Rio de Janeiro, 2020. 52p. Dissertação de Mestrado - Departamento de Economia , Pontifícia Universidade Católica do Rio de Janeiro.

Entender a formação da estrutura a termo da taxa de juros é de suma importância para a autoridade monetária e demais agentes do mercado. No presente trabalho, replicamos o modelo proposto por Adrian, Crump e Moench (2013) para decompor a curva de juros brasileira e criar séries históricas para as expectativas das taxas de juros futuras, e para os prêmios de risco variantes no tempo. Este modelo gaussiano afim de 5 fatores latentes estima a curva de juros brasileira a partir de um método por mínimos quadrados ordinários em três etapas e obtém a precificação neutra ao risco. Por fim, apesar de a literatura empírica de macroeconomia e finanças reconhecer as limitações dos modelos gaussianos afins, nossas previsões fora da amostra apresentaram resultados ligeiramente superiores ao modelo de random walk.

\section{Palavras-chave}

Prêmio de Risco; Expectativa; Curva de Juros; Modelo Gaussiano Afim; 


\section{Abstract}

Mattos Martins, Breno Maurício; Gomes Pinto Garcia, Márcio (Advisor). Decomposing the Brazilian Yield Curve. Rio de Janeiro, 2020. 52p. Dissertação de mestrado - Departamento de Economia, Pontifícia Universidade Católica do Rio de Janeiro.

Understanding the term structure of interest rate has an important role as a tool for the monetary authority and other market players. In the present work, we replicate the model proposed by Adrian, Crump and Moench (2013) to decompose the Brazilian yield curve and create historical series for expectations of future interest rates, and for time-varying risk premiums. This five-factor Gaussian model estimates the Brazilian yield curve using a three-step ordinary least squares method and obtains riskneutral pricing. Finally, although the empirical macroeconomics and finance literature recognizes the limitations of Affine models, our out-of-sample estimations showed results slightly superior to the random walk model.

\section{Keywords}

Risk Premium; Expectations; Yield Curve; Gaussian Affine Model. 


\section{Sumário}

1 Introdução 11

2 Revisão de Literatura $\quad 13$

2.1 Hipótese das Expectativas 13

2.1.1 Literatura empírica sobre a Hipótese das Expectativas 13

2.2 Modelos para estimação do prêmio de risco da curva de juros 14

$\begin{array}{lll}2.2 .1 & \text { Regressões Lineares } & 14\end{array}$

2.2.2 Pesquisa com participantes do mercado 15

$\begin{array}{ll}2.2 .3 \text { Modelos gaussianos afim } & 16\end{array}$

3 Metodologia e Dados $\quad 19$

3.1 Notações e conceitos básicos 19

$\begin{array}{lll}3.1 .1 & \text { Curva de juros } & 19\end{array}$

3.1.2 Notações de preço, yield, forward e excesso de retorno 21

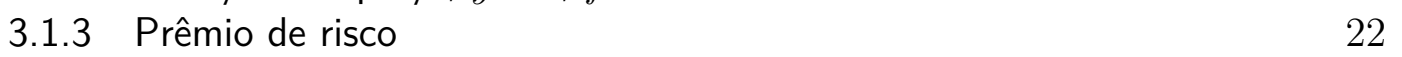

3.2 Modelo para estimação do prêmio de risco 23

3.2.1 Variáveis de estado, retornos esperados e preço de mercado do risco 23

3.2.2 Estimação dos parâmetros 26

$\begin{array}{ll}\text { 3.2.3 Modelo gaussiano afim } & 27\end{array}$

4 Resultados $\quad 29$

4.1 Análise dos componentes principais 29

4.2 Estimações dos excessos de retornos e preços de mercado do risco 31

4.2.1 Excessos de retornos 32

4.2.2 Preços de mercado do risco 32

4.3 Decomposição da curva de juros 34

4.4 Previsões fora da amostra 41

5 Conclusão 44

$\begin{array}{lll}\text { A } & \operatorname{VAR}(1) \text { dos componentes principais } & 47\end{array}$

$\begin{array}{lll}\text { B } & \text { Regressões dos excessos de retornos } & 48\end{array}$ 


\section{Lista de figuras}

Figura 2.1 Prêmio de risco para maturidade de 10 anos nos EUA. 18

Figura 3.1 Taxas referenciais dos swaps prefixados vs DI. 20

Figura 4.1 Análise dos coeficientes dos componentes principais. $\quad 30$

Figura 4.2 Primeiro componente principal vs Nível da ETTJ. 30

Figura 4.3 Segundo componente principal vs Inclinação da ETTJ. 31

Figura 4.4 Terceiro componente principal vs Curvatura da ETTJ. 31

Figura 4.5 Parâmetros de $\widehat{\widehat{\lambda_{0}}}$.

Figura 4.6 Parâmetros de $\widehat{\lambda_{1}}$. 33

Figura 4.7 Yield de 2 anos estimado vs observado. 34

Figura 4.8 Yield de 5 anos estimado vs observado. 35

Figura 4.9 Yield de 10 anos estimado vs observado. 35

Figura 4.10 Yield de 2 anos vs neutro ao risco. 36

Figura 4.11 Yield de 5 anos vs neutro ao risco. 37

Figura 4.12 Yield de 10 anos vs neutro ao risco. 37

Figura 4.13 Estimação do prêmio de risco de 2 anos. 38

Figura 4.14 Estimação do prêmio de risco de 5 anos. 38

Figura 4.15 Estimação do prêmio de risco de 10 anos. 39

Figura 4.16 Previsão fora da amostra 2 anos: modelo vs random walk. 41

Figura 4.17 Previsão fora da amostra 5 anos: modelo vs random walk. 42

Figura 4.18 Previsão fora da amostra 10 anos: modelo vs random walk. 


\section{Lista de tabelas}

Tabela 3.1 Parâmetros estimados por Svensson (1995). 21

$\begin{array}{lll}\text { Tabela 4.1 Análise dos componentes principais. } & 29\end{array}$

Tabela 4.2 EQM dos modelos 43

Tabela A.1 VAR(1) dos cinco componentes principais. 47

Tabela B.1 Regressão do excesso de retorno do yield de 6 meses. $\quad 48$

Tabela B.2 Regressão do excesso de retorno do yield de 12 meses. $\quad 49$

Tabela B.3 Regressão do excesso de retorno do yield de 18 meses. 49

Tabela B.4 Regressão do excesso de retorno do yield de 24 meses. $\quad 50$

Tabela B.5 Regressão do excesso de retorno do yield de 36 meses. $\quad 50$

Tabela B.6 Regressão do excesso de retorno do yield de 48 meses. $\quad 51$

Tabela B.7 Regressão do excesso de retorno do yield de 60 meses. $\quad 51$

Tabela B.8 Regressão do excesso de retorno do yield de 84 meses. $\quad 52$

Tabela B.9 Regressão do excesso de retorno do yield de 120 meses. $\quad 52$ 


\section{Lista de Abreviaturas}

ETTJ - Estrutura a Termo da Taxa de Juros

LTN - Letras do Tesouro Nacional

NTN-F - Notas do Tesouro Nacional Série F

DI - Depósitos Interbancários

B3 - Brasil, Bolsa e Balcão

CETIP - Central de Custódia e Liquidação Financeira de Títulos

VAR - Vetor autorregressivo

OLS - Mínimos quadrados ordinários

EQM - Erro Quadrático Médio

PEC - Proposta de Emenda Constitucional 


\section{Introdução}

A estrutura a termo da taxa de juros (ETTJ) é a relação, em um determinado período, entre as taxas de juros de diferentes prazos de vencimento de títulos de renda fixa, normalmente associada a ativos que paguem juros apenas no vencimento, ou seja, a partir de zero-coupon bonds. Um dos temas mais estudados na literatura de macroeconomia e finanças tem sido a relação entre as taxas de juros de curto prazo e de longo prazo. De acordo com Cox et al. (1985) , entender o processo de formação da curva de juros é importante ao mercado financeiro para precificação dos investimentos, aos demais setores da economia cujos projetos serão financiadas com base na ETTJ, e às autoridades monetárias na condução da política monetária, sendo possível que estas acompanhem as expectativas dos agentes do mercado. Não obstante ao fato de o Banco Central utilizar a taxa de juros de curto prazo para condução da política monetária, Shousha (2008) destaca que o custo de crédito das firmas e famílias dependem das taxas de juros para diferentes prazos e, consequentemente, as taxas de longo prazo são mais importantes para determinar o impacto sobre a demanda agregada. Portanto, é fundamental entender as dinâmicas da curva de juros para tomar decisões de alocação de capital e/ou formular políticas econômicas adequadas.

$\mathrm{Na}$ literatura empírica de macroeconomia e finanças, os primeiros trabalhos desenvolvidos para estudo da ETTJ testaram a validade da Hipótese das Expectativas, e com a sua rejeição, a literatura empírica avançou sobre o estudo do prêmio de risco variante no tempo. Neste trabalho, buscamos construir uma série histórica para as variações temporais dos prêmios de risco das diversas maturidades da ETTJ e para as expectativas futuras das taxas de juros. Posteriormente, apresentamos previsões fora da amostra para a curva de juros e a comparamos com modelos de passeio aleatório.

Ainda que as autoridades monetárias realizem pesquisas com participantes de mercado ${ }^{1}$, este instrumento apresenta certas deficiências. As revisões das projeções dos analistas são realizadas com baixa frequência e, por isto, com atrasos em relação aos movimentos do mercado e divulgação das informações. Estas condições podem atrapalhar as análises comparativas entre as projeções

${ }^{1} \mathrm{O}$ Banco Central do Brasil utiliza a pesquisa Focus, por exemplo. 
dos economistas e os preços de mercado, principalmente para vencimentos mais longos.

Neste trabalho, foi adaptado para a ETTJ brasileira o modelo proposto por Adrian et al. (2013). É um modelo gaussiano afim, cujas taxas de juros são funções lineares das variáveis latentes. Esta família de modelos permite, a partir da hipótese de não-arbitragem, estimar a dinâmica das taxas de juros dos diversos prazos. Uma possível limitação para estes tipos de modelos é pelo fato de apenas utilizarem variáveis latentes para explicar os movimentos da curva de juros. Entretanto, a sua utilização tem se revelado adequada para estimação do prêmio de risco.

No próximo capítulo, apresento uma revisão de literatura sobre as teorias para formação da curva de juros e estudos para estimações do prêmio de risco. No capítulo 3, apresento a base de dados utilizada e a metodologia proposta por Adrian et al. (2013).

No capítulo 4, apresento as estimações neutras ao risco e as comparo com os dados observados. Os resultados obtidos para o período amostral sugerem que os prêmios de risco médios das maturidades de 2 anos, 5 anos e 10 anos são, respectivamente, $0.65 \%, 1.86 \%$ e 3.30\%. Também é possível verificar o aumento nos níveis dos prêmios de risco em períodos caracterizados pela piora das condições financeiras internacionais e/ou piora do cenário fiscal doméstico. Por último, as previsões fora da amostra apresentaram resultados ligeiramente superiores às previsões por random walk. 


\section{2}

\section{Revisão de Literatura}

\section{1}

\section{Hipótese das Expectativas}

A teoria mais antiga e amplamente testada por diversos autores sobre a formação da estrutura a termo da taxa de juros é a Hipótese das Expectativas ${ }^{1}$. Ao assumir inexistência de oportunidades de arbitragens e a neutralidade ao risco dos agentes, a Hipótese das Expectativas sugere que as taxas de juros de longo prazo são formadas pela média das expectativas das futuras taxas de curto prazo. Em sua forma fraca, assume a existência de um prêmio de risco constante para cada vencimento e que não varia no tempo. Desta forma, variações na curva de juros são explicadas por mudanças nas expectativas dos agentes e a inclinação da curva é determinada pelas expectativas do mercado quanto às taxas à vista futuras. Portanto, a taxa de juros no tempo $t$ e com vencimento em $n$ períodos a frente pode ser definida como:

$$
y_{t}^{(n)}=\frac{1}{n} \sum_{i=0}^{n-1} E_{t}\left(y_{t+i}^{(1)}\right)+p r_{t}
$$

Onde: $y_{t}^{(n)}$ é a taxa de juros de $n$ períodos no instante t, $y_{t+i}^{(1)}$ é a taxa de juros de cada período $t+i$ até $t+i+1, E_{t}$ é a esperença condicional com informações conhecidas até o período $t$ e $p r_{t}$ é o prêmio de risco do prazo $n$.

\subsection{1}

\section{Literatura empírica sobre a Hipótese das Expectativas}

A literatura empírica de macroeconomia e finanças, a partir da década de 1980, através de diversos estudos, testou a Hipótese das Expectativas para diferentes regiões. Fama e Bliss (1987), por exemplo, utilizaram títulos do tesouro americano com maturidades entre um e cinco anos para testar a validade da Hipótese das Expectativas. O objetivo da pesquisa era responder duas importantes perguntas: a) se as taxas forward possuem informações sobre as taxas de juros futuras; b) e se as taxas forward possuem informações sobre a estrutura de retornos esperados dos títulos de diferentes maturidades. Os resultados obtidos por Fama e Bliss (1987) sugerem que os excessos de

${ }^{1}$ Abordada inicialmente por Fisher (1896). 
retornos são diferentes de zero e variantes ao longo do tempo, contrariando a Hipótese das Expectativas.

Campbell e Shiller (1991), examinaram se a inclinação da curva de juros americana possui poderes preditivos sobre as mudanças nas taxas de juros, com títulos do tesouro americano de diversas maturidades, conforme é sugerido pela Hipótese das Expectativas. Os resultados para qualquer maturidade compreendida entre um mês e dez anos, sugerem que quando o spread entre a taxa curta e a taxa longa é suficientemente elevado, o yield do título de longo prazo tende a se reduzir, contrariando a hipótese das expectativas, enquanto as taxas de curto prazo tendem a subir, de acordo com a a Hipótese das Expectativas.

Tabak e de Andrade (2003) analisaram a Hipótese das Expectativas para o caso brasileiro e trabalharam com os títulos de prazos de dois a doze meses para o período entre 1995 e 2000. Os autores verificaram que os prêmios de risco da curva de juros são positivamente relacionados com o diferencial coberto e volatilidade da taxa de juros e, desta forma, os resultados sugerem rejeição da Hipótese das Expectativas, especialmente nos prazos mais longos.

Brito et al. (2003) também estudaram a validade da Hipótese das Expectativas para o caso do Brasil, utilizando prazos entre um dia e um ano, e testes simalares aos propostos por Campbell e Shiller (1991). Em suma, os resultados apresentam divergências em relação à Hipótese das Expectativas e deixam a discussão em aberto para o caso brasileiro.

A rejeição da Hipótese das Expectativas em diversos estudos para diferentes regiões, fez com crescesse o interesse da literatura empírica de macroeconomia e finanças sobre a modelagem do prêmio de risco variante no tempo para diferentes prazos de maturidade.

\section{2}

\section{Modelos para estimação do prêmio de risco da curva de juros}

\subsection{1}

\section{Regressões Lineares}

Assim como os trabalhos de Fama e Bliss (1987) e Campbell e Shiller (1991) para validação da Hipótese das Expectativas, a literatura empírica sobre o prêmio de risco presenciou o desenvolvimento de diversos modelos baseados em regressões lineares. Cochrane e Piazzesi (2005) utilizaram combinação lineares de taxas de juros futuras para estudar a variação do excesso de retorno esperado dos títulos do tesouro americano no tempo, não relacionadas aos movimentos do nível, inclinação e curvatura da estrutura a termo da 
taxa de juros. Os resultados obtidos por Cochrane e Piazzesi (2005) sugerem previsibilidade no excesso de retorno de títulos entre 1 e 5 anos de maturidade com $R^{2}$ de até 0,44 .

Piazzesi e Swanson (2008) demonstram que o excesso de retorno dos títulos do tesouro americano possui forte componente contracíclico e $R^{2}$ de até 0,39 . O modelo proposto pelos autores regride o excesso de retorno destes títulos com os dados do relatório do mercado de trabalho dos EUA, spreads dos títulos do tesouro americano e de títulos corporativos.

Ainda que os modelos de regressão linear permitam estimação do excesso de retorno dos títulos, eles possuem deficiência em montar uma estrutura com os componentes de expectativa futura dos juros.

\subsection{2}

\section{Pesquisa com participantes do mercado}

Uma possibilidade para obtenção da expectativa futura das taxas de juros é a utilização das projeções dos participantes de mercados para as principais variáveis macroeconômicas. No Brasil, por exemplo, utiliza-se o relatório Focus. No limite, caso estas pesquisas reflitam de forma correta as expectativas do mercado, ou seja, sem vieses ou erros de preenchimento, o prêmio de risco da curva de juros poderá ser obtido através da diferença entre as taxas dos títulos e as expectativas dos agentes. Desta forma, é comum que esta literatura que utilize as expectativas registradas como proxy para expectativas do mercado.

Kim e Orphanides (2005) utilizaram as projeções, publicadas pela Blue Chip Financial Forecasts dos títulos de 3 meses do tesouro americano para estimação de um modelo gaussiano afim de três fatores. Em geral, o modelo gera estimativas estáveis para a taxa de curto prazo e captura algumas das variações no curto prazo para mudanças nas expectativas das taxas de juros de longo prazo.

Wright (2011) constrói um painel de títulos zero-coupon para 10 países industrializados durante duas décadas. O autor utiliza dois métodos distintos para as estimações: i) modelo gaussiano afim; ii) modelo baseado nas expectativas do mercado. Os resultados sugerem que o prêmio de risco se reduziu internacionalmente ao longo do período, especialmente nos países que conseguiram reduzir os riscos relacionados à inflação, através de mudanças no framework de política monetária.

Crump et al. (2016) utilizam as expectativas dos agentes de mercado registradas na US Survey of Professional Forecasters ${ }^{2}$ como as expecta-

${ }^{2}$ Pesquisa de projeções macroeconômicas mais antiga dos EUA. É realizada trimestralmente pelo Federal Reserve Bank of Philadelphia. 
tivas para as taxas de juros futuras. Desta forma, os autores definem que o prêmio de risco corresponde à diferença entre as taxas dos títulos do tesouro americano e a média das expectativas dos agentes de mercado, de acordo com a pesquisa. Os resultados sugerem que a maior parte dos movimentos nos rendimentos dos títulos de renda fixa está relacionada às variações nos prêmios de risco das diversas maturidades da curva de juros e, por isto, a importância do seu estudo.

As grandes desvantagens desta metodologia para estimação da trajetória das expectativas da taxa de juros futura e dos prêmios de risco estão relacionadas à frequência de atualização destas pesquisas, que podem assumir caráter inercial, e com a ponderação das projeções, que muitas vezes não refletem os diferentes tamanhos dos participantes do mercado.

\subsection{3}

\section{Modelos gaussianos afim}

Por outro lado, os modelos gaussianos do tipo afim têm se mostrado bastante eficientes na estimação das expectativas das taxas de juros futuras e, consequentemente, dos prêmios de risco. Estes modelos utilizam a hipótese de não-arbitragem, ou seja, não é possível que se obtenha retornos diferentes entre um título de maturidade $n$ e uma carteira composta por outros títulos que, de alguma forma, repliquem o título de maturidade $n$. Da mesma forma como em alguns modelos de regressão linear, os modelos gaussianos do tipo afim também utilizam os componentes principais para estimação da estrutura a termo da taxa de juros. Portanto, como é descrito por Adrian et al. (2013), os modelos gaussianos do tipo afim seguem a hipótese de que o fator estocástico de desconto é exponencialmente afim, ou seja, os yields dos títulos dependem linearmente dos fatores. Outras duas hipóteses também são assumidas: os preços de mercado do risco são do tipo afim nas variáveis de estado; e os resíduos seguem uma distruibuição gaussiana. Adrian et al. (2013) também chamam atenção para o fato de que os modelos afim da estrutura a termo da taxa de juros usualmente utilizam o método da máxima verossimilhança para estimação dos fatores e parâmetros do modelo.

Dai e Singleton (2000), por exemplo, contribuíram para que a literatura empírica avançasse sobre este tema. Em seu trabalho, os autores demonstram como, até então, muitos modelos do tipo afim não conseguiam descrever as importantes características da distribuição das taxas de curto e longo prazos. A fonte da especificação incorreta do modelo é por conta de restrições excessivamente fortes nas correlações entre as variáveis de estado. 
Duffee (2002) descreve que os modelos gaussianos do tipo afim produzem previsões ruins pois a remuneração pelo risco é derivada da variação do risco e, desta forma, a compensação pelo risco não pode variar independentemente da volatilidade da taxa de juros. Os resultados obtidos sugerem que as melhores previsões são geradas quando assume-se que as taxas de rendimentos dos títulos seguem um passeio aleatório.

Kim e Wright (2005) desenvolveram um modelo simples de três fatores, utilizado pela equipe do Federal Reserve, para analisar os yields dos títulos do tesouro dos EUA desde 1990. O modelo sugere que grande parte da redução das taxas longas ao longo do período se deve à redução do prêmio de risco dos títulos do tesouro dos EUA. Mais especificamente, os resultados obtidos para as estimações realizadas para o período compreendido entre os dias 29 de junho de 2004 e 20 de julho de 2005, sugerem que a forte redução da taxas longas foi reflexo de uma redução maior do prêmio de risco e com ligeiro crescimento das expectativas das taxas futuras.

Cochrane e Piazzesi (2009) utilizaram dados dos títulos do tesouro americano e quatro fatores para decompor a curva de juros em expectativas e prêmios de risco. O modelo incorporou, de Cochrane e Piazzesi (2005), a combinação linear dos yields dos títulos e que correspondem à grande parte da variância dos retornos esperados. Os demais fatores são os três componentes principais das taxas de rendimento: nível, inclinação e curvatura.

Por fim, destaco o trabalho elaborado por Adrian et al. (2013) que demonstra como precificar e decompor as séries temporais da estrutura a termo da taxa de juros através da estimação por mínimos quadrados ordinários (OLS) em três etapas. Os autores também apresentaram testes de especificações que foram favoráveis a utilização de cinco componentes principais como fatores de precificação da curva de juros. Esta metodologia permite ganhos de eficiência computacional na estimação da estrutura a termo da taxa de juros com alto número de fatores. Mais especificamente, Adrian et al. (2013) demonstram que este modelo obtém resultados superiores às estimações out-of-sample obtidas pelo modelo de quatro especificações, formulado por Cochrane e Piazzesi (2009), para as dinâmicas do prêmio de risco e expectativa das taxas de juros futuras. 
Figura 2.1: Prêmio de risco para maturidade de 10 anos nos EUA.

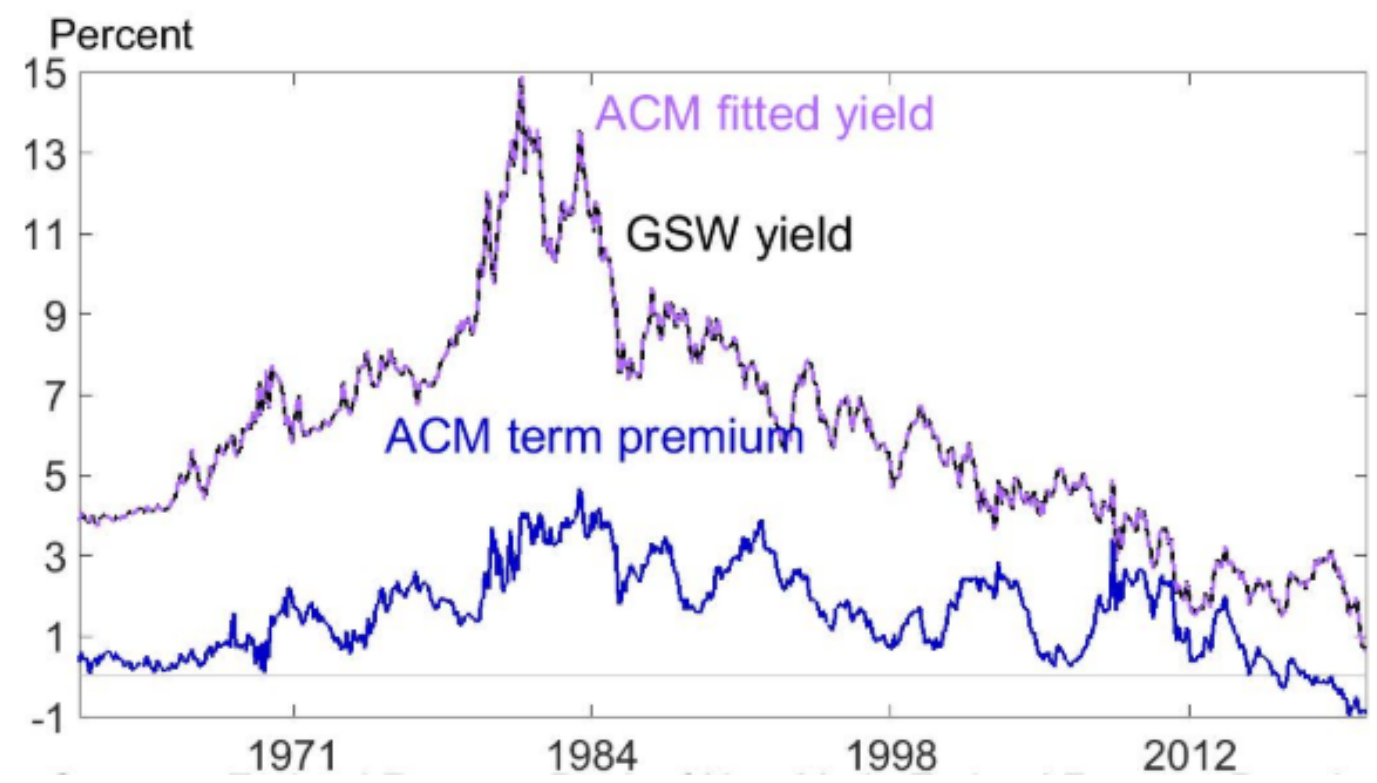

A figura 2.1 apresenta o prêmio de risco para a maturidade de 10 anos, estimado pelo modelo proposto por Adrian et al. (2013) para os EUA. Fonte: Federal Reserve Bank of New York.

Apesar de os modelos gaussianos do tipo afim não incorporarem variáveis macroeconômicas na estimação da curva de juros, estes permitem gerar boas estimações para a decomposição da estrutura a termo em expectativa das taxas de juros futuras e prêmio de risco. Em especial, ressaltamos os resultados obtidos por Adrian et al. (2013). No próximo capítulo, iremos apresentar a metodologia proposta por estes autores e adaptar este modelo às especificidades da estrutura a termo da taxa de juros brasileira, sob a proposta de se construir séries históricas das expectativas da taxas de juros futuras e dos prêmios de risco variantes no tempo para diversos prazos de maturidade. 


\section{3 \\ Metodologia e Dados}

\section{1}

Notações e conceitos básicos

\subsection{1}

\section{Curva de juros}

A literatura de macroeconomia e finanças usualmente supõe que os títulos de renda fixa emitidos pelo governo são livres do risco de crédito, ou seja, sem risco de inadimplência. Para o caso brasileiro, os títulos de renda fixa prefixados, Letras do Tesouro Nacional (LTN) e Notas do Tesouro Nacional Série F (NTN-F), são considerados como ativos livre de risco e poderiam ser utilizados para construção da ETTJ. Entretanto, o mercado de derivativos das taxas de depósitos interbancários (DI) da B3 (Brasil, Bolsa e Balcão) é um dos mais importantes e líquidos do mercado brasileiro, e é normalmente utilizado como referência para construção da curva de juros.

A taxa DI é a taxa média das operações interbancárias de empréstimos de um dia, apuradas pela CETIP (Central de Custódia e Liquidação Financeira de Títulos). Os contratos derivativos de DI são do tipo zero-coupon, as taxas negociadas são muito próximas dos títulos públicos e a correlação é próxima a 1. Para o presente trabalho, utilizamos as taxas referenciais diárias dos swaps prefixados com DI, para os vencimentos de 90 dias (3 meses), 180 dias (6 meses), 360 dias (1 ano), 540 dias (1,5 ano), 720 dias (2 anos), 1080 dias (3 anos), 1440 dias (4 anos), 1800 dias ( 5 anos), 2520 dias (7 anos) e 3600 dias (10 anos), referente ao período compreendido entre outubro de 2009 e abril de 2020, conforme ilustrado na figura 3.1.

De forma a evitar erros, possíveis distorções e para obter os yields em quaisquer horizontes, interpolamos as taxas de acordo com o modelo paramétrico proposto por Svensson (1995) e obtemos os yields referentes ao período compreendido entre 1 mês e 120 meses (10 anos), conforme equação abaixo: 
$R_{t}(\tau)=\alpha_{1 t}+\alpha_{2 t}\left(\frac{1-e^{-\delta_{t} \tau}}{\delta_{t} \tau}\right)+\alpha_{3 t}\left(\frac{1-e^{-\delta_{t} T}}{\delta_{t} \tau}-e^{-\delta_{t} \tau}\right)+\alpha_{4 t}\left(\frac{1-e^{-\delta \lambda_{2 t} \tau}}{\delta_{2 t} \tau}-e^{-\delta_{2 t} \tau}\right)$

Os coeficientes $\alpha_{1}, \alpha_{2}, \alpha_{3}$ e $\alpha_{4}$ podem ser interpretados como elementos da curva de juros, ou seja, como o nível, a inclinação, a curvatura e a convexidade da ETTJ. Os parâmetros $\delta_{1}$ e $\delta_{2}$ são os fatores de decaimento e determinam os pontos de máximo das curvaturas. As estatísticas descritivas dos parâmetros estimados pelo modelo estão na tabela 3.1.

Figura 3.1: Taxas referenciais dos swaps prefixados vs DI.

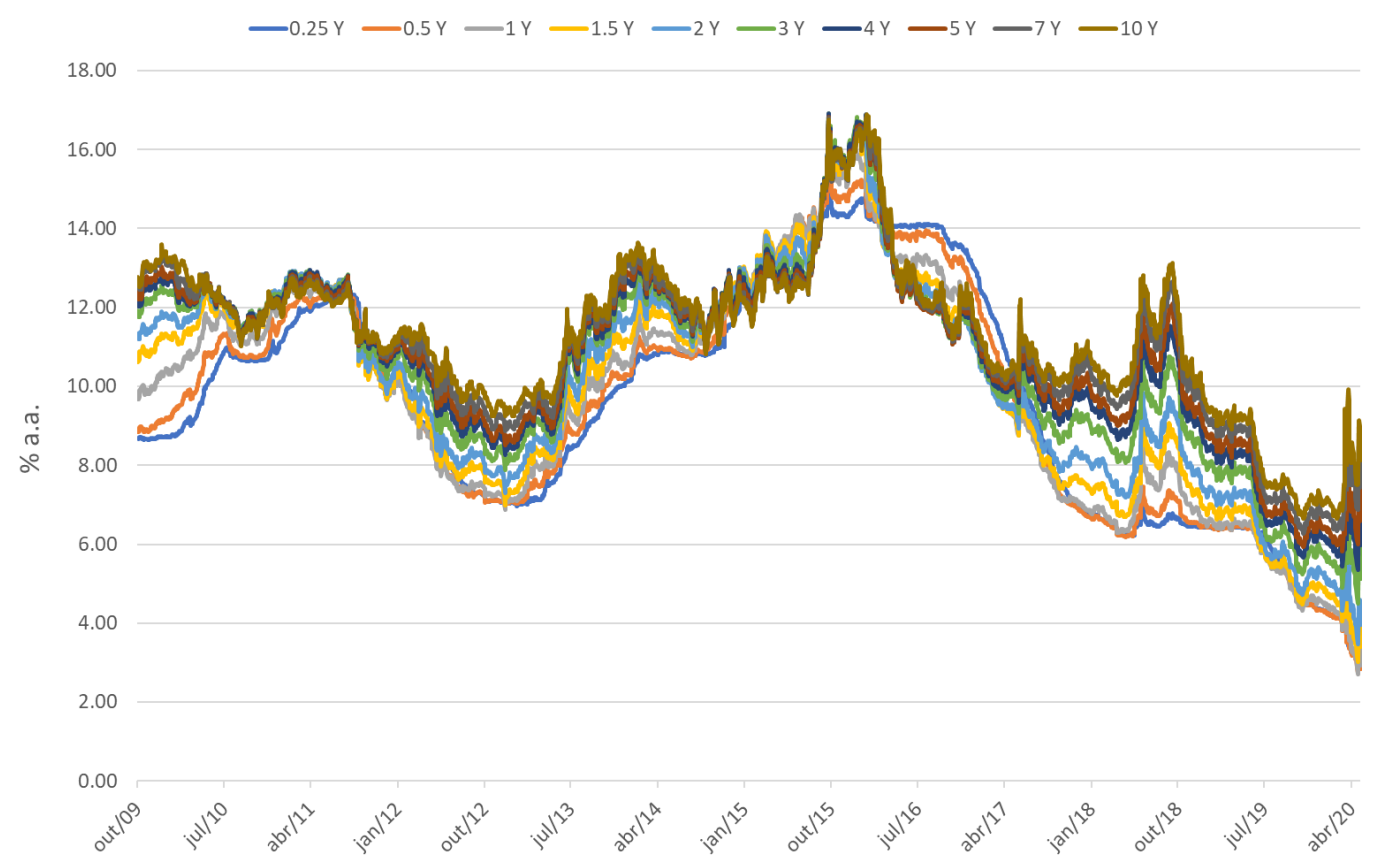

A figura 3.1 apresenta as taxas dos swaps prefixados vs DI, negociadas na B3. As taxas são cotadas como zero-coupon bond. Abaixo, apresentamos os vértices escolhidos para representarem as partes curta, intermediária e longa da curva de juros. Fonte: Bloomberg, B3. Elaboração própria. 
Tabela 3.1: Parâmetros estimados por Svensson (1995).

\begin{tabular}{|c|c|c|c|c|c|c|}
\hline Estatísticas & $\alpha_{1}$ & $\alpha_{2}$ & $\alpha_{3}$ & $\alpha_{4}$ & $\delta_{1}$ & $\delta_{2}$ \\
\hline \hline Máximo & 0.226 & 0.029 & 0.355 & 2.857 & 6.720 & 3.077 \\
Mínimo & 0.074 & -0.125 & -2.892 & -0.351 & 0.523 & 0.030 \\
Média & 0.120 & -0.022 & -0.032 & -0.010 & 2.027 & 0.950 \\
Mediana & 0.119 & -0.023 & -0.045 & -0.015 & 1.750 & 0.796 \\
Desvio padrão & 0.021 & 0.023 & 0.087 & 0.089 & 0.835 & 0.655 \\
\hline
\end{tabular}

A tabela 3.1 apresenta as estatísticas descritivas dos seis parâmetros estimados pelo modelo de Svensson (1995) para interpolação da curva de juros brasileira.

\subsection{2}

Notações de preço, yield, forward e excesso de retorno

Comumente, os modelos de macroeconomia e finanças adotam escala logarítmica para precificação de bonds, de forma a facilitar os cálculos. Desta forma, seja $P_{t}^{(n)}$ o preço do título com vencimento em $n$ no período $t, p_{t}^{(n)}$ é o $\log$ do preço:

$$
p_{t}^{(n)}=\log \left(P_{t}^{(n)}\right)
$$

Como estamos trabalhando em escala logarítmica, as taxas são capitalizadas continuamente. Portanto, $y_{t}^{(n)}$ é o log do yield (taxa de rendimento) do título de $n$ anos no período $t$ e definido como:

$$
y_{t}^{(n)}=-\frac{1}{n}\left(p_{t}^{(n)}\right)
$$

A taxa forward, que pode ser definida como a taxa de juros entre dois vencimentos, $n$ e $n+1$, no período $t$ e é definida por $f_{t}^{(n, n+1)}$ :

$$
f_{t}^{(n, n+1)}=p_{t}^{(n)}-p_{t}^{(n+1)}
$$

O retorno do título com maturidade $n$ entre os períodos $t$ e $t+1$ é dado por: 


$$
r_{t+1}^{(n)}=p_{t+1}^{(n-1)}-p_{t}^{(n)}
$$

Por fim, o excesso de retorno do título com maturidade $n$ entre os períodos $t$ e $t+1$ é definido como:

$$
r x_{t+1}^{(n)}=\left[p_{t+1}^{(n-1)}-p_{t}^{(n)}\right]-y_{t}^{(n)}
$$

\subsection{3}

\section{Prêmio de risco}

O prêmio de risco pode ser interpretado como o retorno adicional que o mercado exige ao alocar capital em ativos arriscados e, consequentemente, o tamanho do prêmio está relacionado ao nível de risco. Cochrane e Piazzesi (2009) definem as diferenças entre prêmio de risco do yield, prêmio de risco do forward e retorno do prêmio de risco. Podemos decompor a taxa de juros em um componente de expectativa futura dos juros e um componente de prêmio de risco. Comumente, existem três maneiras convencionais de demonstrar o prêmio de risco e que possuem interpretações em termos de portfólio.

O prêmio de risco do yield é a diferença entre o yield de um título zerocoupon de $n$ anos no período $t$ e a expectativa em $t$ da taxa de juros média, como em (2-1). Isto equivale ao retorno médio esperado de se carregar um título zero-coupon com vencimento em $n$ anos, financiados pela venda de títulos de 1 ano em sequência, até o vencimento.

O prêmio de risco da taxa forward é o retorno esperado de se carregar um título de $n$ anos, financiado pela venda de um título de $n-1$ anos até o vencimento. Equivalente ao retorno esperado de se financiar por um ano no mercado futuro do spot e emprestar no mercado a termo:

$$
f_{t}^{(n)}=E_{t}\left(y_{t+n-1}^{(1)}\right)+r p f_{t}^{(n)}
$$

O prêmio de risco do retorno é o prêmio de carregamento do título de $n$ anos por um ano, desde que financiado pelo título de 1 ano: 


$$
E_{t}\left(r_{t+1}^{(n)}\right)=y_{t}^{(1)}+r p r_{t}^{(n)}
$$

\section{2}

\section{Modelo para estimação do prêmio de risco}

Nesta dissertação, aplicou-se o modelo proposto Adrian et al. (2013) de cinco fatores ao caso brasileiro. Os autores demonstram que o processo de estimação por mínimos quadrados ordinários em três etapas permite ganhos de eficiência e a utilização de cinco fatores para precificação da curva de juros.

\subsection{1}

\section{Variáveis de estado, retornos esperados e preço de mercado do risco}

O modelo proposto por Adrian et al. (2013) assume que a dinâmica de um vetor $K$ x 1 das variáveis de estado $X_{t}$ evolua de acordo com o seguinte vetor autorregressivo (VAR), em que $K=5$ corresponde ao número de fatores utilizados, ou seja, do número de componentes principais:

$$
X_{t+1}=\mu+\Phi X_{t}+v_{t+1}
$$

A especificação da evolução dinâmica das variáveis de estado pode ser interpretada como em tempo discreto. Os choques $v_{t+1}$ seguem condicionalmente uma distribuição Gaussiana com matriz de variância-covariância $\Sigma$ :

$$
v_{t+1} \mid\left\{X_{s}\right\}_{s=0}^{t} \sim N(0, \Sigma)
$$

Em que $\left\{X_{s}\right\}_{s=0}^{t}$ denota o histórico de $X_{t}$. A hipótese de não-arbitragem implica na existência de um fator estocástico de desconto $M_{t}$, tal que:

$$
P_{t}^{(n)}=E_{t}\left[M_{t+1} P_{t+1}^{(n-1)}\right]
$$

Combinando a equação (3-2) e a equação (3-11), e assumindo que o fator estocástico de desconto $M_{t+1}$ seja exponencialmente afim, temos que: 


$$
M_{t+1}=\exp \left(-y_{t}-\frac{1}{2} \lambda_{t}^{\prime} \lambda_{t}-\lambda_{t}^{\prime} \Sigma^{-1 / 2} v_{t+1}\right)
$$

Assume-se ainda que os preços de mercado do risco seguem a seguinte forma afim:

$$
\lambda_{t}=\Sigma^{-1 / 2}\left(\lambda_{0}+\lambda_{1} X_{t}\right)
$$

Combinando as equações (3-6) e (3-12), obtemos:

$$
1=E_{t}\left[\exp \left(r x_{t+1}^{(n)}-\frac{1}{2} \lambda_{t}^{\prime} \lambda_{t}-\lambda_{t}^{\prime} \Sigma^{-1 / 2} v_{t+1}\right)\right]
$$

Se assumirmos que $r x_{t+1}^{(n)}$ e $v_{t+1}$ seguem, conjuntamente, uma distruibuição normal, encontramos:

$$
E_{i}\left[r x_{i+1}^{(n-1)}\right]=\operatorname{Cov}_{t}\left[r x_{i+1}^{(n-1)}, v_{t+1}^{\prime} \Sigma^{-1 / 2} \lambda_{t}\right]-\frac{1}{2} \operatorname{Var}\left[r x_{i+1}^{(n-1)}\right]
$$

Podemos reescrever a equação (3-15), substituindo $\operatorname{Cov}_{t}\left[r x_{t+1}^{(n)}, v_{t+1}^{\prime}\right] \Sigma^{-1}$ por $\beta_{t}^{(n)^{\prime}}$ :

$$
E_{t}\left[r x_{t+1}^{(n-1)}\right]=\beta_{t}^{(n-1)^{\prime}}\left(\lambda_{0}+\lambda_{1} X_{t}\right)-\frac{1}{2} \operatorname{Var}_{t}\left[r x_{t+1}^{(n-1)}\right]
$$

A partir da equação (3-16), podemos decompor o excesso de retorno não esperado em um componente correlacionado com $v_{t+1} \mathrm{e}$ em outro componente que é condicionalmente ortogonal, tal que:

$$
r x_{t+1}^{(n-1)}-E_{t}\left[r x_{t+1}^{(n-1)}\right]=\beta_{t}^{(n-1)^{\prime}} v_{t+1}+e_{t+1}^{(n-1)}
$$


Assumimos, também, que os erros dos excessos de retornos esperados $e_{t+1}^{(n)}$ sejam i.i.d., ou seja, condicionalmente independentes e indenticamente distribuídos, e tenham variância $\sigma^{2}$.

Adrian et al. (2013) utilizam as combinações lineares dos componentes principais do log dos yields como fatores observáveis $X_{t}$ e estima os parâmetros do modelo usando retornos de carrego dos títulos em determinado período com base no mesmo conjunto de yields. Isto implica que $\beta_{t}=\beta$, ou seja, $\beta$ é uma constante. Então, o processo gerador para o log do excesso de retorno do carrego do título no período é dado por:

$$
r x_{t+1}^{(n-1)}=\beta^{(n-1)^{\prime}}\left(\lambda_{0}+\lambda_{1} X_{t}\right)-\frac{1}{2}\left[\beta^{(n-1)^{\prime}} \Sigma \beta^{(n-1)}+\sigma^{2}\right]+\beta^{(n-1)^{\prime}} v_{t+1}+e_{t+1}^{(n-1)}
$$

Em que, $\beta^{(n-1)^{\prime}}\left(\lambda_{0}+\lambda_{1} X_{t}\right)$ é interpretado como o retorno esperado, $-\frac{1}{2}\left[\beta^{(n-1)^{\prime}} \Sigma \beta^{(n-1)}+\sigma^{2}\right]$ é o ajuste da convexidade da curva de juros, $\beta^{(n-1)^{\prime}} v_{t+1}$ são os choques sobre o retorno e $e_{t+1}^{(n)}$ é o erro dos excessos de retornos esperados.

Ao combinar este sistema entre as diferentes maturidades e períodos do tempo, podemos reescrever a equação (3-18) como:

$$
r x=\beta^{\prime}\left(\lambda_{0}+\lambda_{1} X\right)-\frac{1}{2}\left[B^{*} \operatorname{vec}(\Sigma)+\sigma^{2}\right]+\beta^{\prime} V+E
$$

Em que, $r x$ é a matriz $N \times T$ de excesso de retorno, $\beta=$ $\left[\beta^{(1)}, \beta^{(2)}, \ldots, \beta^{(n)}\right]$ é a matriz $K \times N$ dos factor loadings ${ }^{1}, X=$ $\left[X_{o}, X_{1}, \ldots, X_{t-1}\right]$ é a matriz dos fatores de preços defasadas, $B^{*}=$ $\left[\operatorname{vec}\left(\beta^{(1)} \beta^{(1)^{\prime}}\right), \ldots, \operatorname{vec}\left(\beta^{(n)} \beta^{(n)^{\prime}}\right)\right]^{\prime}$ é a matrix $N$ x $K^{2}, V$ é uma matriz $K \times T$ e $E$ é uma matriz $N \times T$.

${ }^{1}$ Os factor loadings correspondem ao peso de cada componente principal para cada vértice. 


\subsection{2}

\section{Estimação dos parâmetros}

Adrian et al. (2013) propõe um procedimento de três etapas para a estimação dos parâmetros do modelo:

(i) A estimação do VAR (1) na equação (3-9), a partir do método de mínimos quadrados ordinários, que nos permite decompor $X_{t+1}$ em um componente previsível e a inovação $\hat{v}_{t+1}$. Então, contruímos a matriz $\hat{V}$ a partir do agrupamento das inovações, obtidos na primeira estimação, e estimamos uma matriz de variância-covariância das variáveis de estado $\hat{\Sigma}=\hat{V} \hat{V}^{\prime} / T$.

(ii) Na segunda etapa, regredimos o excesso de retorno de um mês em uma constante, nas inovações dos fatores (i) e nos fatores defasados.

$$
r x=a+\beta^{\prime} \hat{V}+c X+E
$$

Em seguida, agrupamos os regressores na matriz $\tilde{Z},(2 K+1) \times T$, em que $\left.\tilde{Z}=\left[\hat{V}^{\prime} X^{\prime}\right]\right]^{\prime}$, então o estimador torna-se:

$$
\left[\hat{a} \hat{\beta}^{\prime} \hat{c}\right]=\operatorname{rx} \tilde{Z}^{\prime}\left(\tilde{Z} \tilde{Z}^{\prime}\right)^{-1}
$$

Posteriormente, coletamos os coeficientes dos resíduos da regressão anterior para a matriz $\widehat{E}$, que possui dimensões $N$ x $T$. Estima-se $\widehat{\sigma}^{2}=\operatorname{traco}\left(\hat{E} \hat{E}^{\prime}\right) / N T$. Desta forma, contruímos $B^{*}$ de $\hat{\beta}$.

(iii) Por fim, estimamos os parâmetros do preço de risco de mercado, $\lambda_{0} \mathrm{e}$ $\lambda_{1}$, através de uma regressão cross-section. Da equação (3-19), temos que $a=\beta^{\prime} \lambda_{0}-\frac{1}{2}\left[B^{*} \operatorname{vec}(\Sigma)+\sigma^{2}\right]$ e $c=\beta^{\prime} \lambda_{1}$. Deste modo, obtemos os estimadores para $\lambda_{0}$ e $\lambda_{1}$ :

$$
\widehat{\lambda_{0}}=\left(\hat{\beta} \hat{\beta}^{\prime}\right)^{-1} \hat{\beta} \quad\left(\hat{a}+\frac{1}{2}\left[B^{*} \operatorname{vec}(\Sigma)+\sigma^{2}\right]\right)
$$


$\mathrm{e}$

$$
\widehat{\lambda_{1}}=\left(\hat{\beta} \hat{\beta}^{\prime}\right)^{-1} \hat{\beta} \hat{c}
$$

Particularmente, se $\widehat{\lambda_{0}}=\widehat{\lambda_{1}}=0$, os investidores são neutros ao risco e a hipótese das expectativas é válida. Se $\widehat{\lambda_{0}} \neq 0$, existe um prêmio de risco e, se $\widehat{\lambda_{1}} \neq 0$ existe um prêmio de risco variante no tempo. Desta forma o resultado esperado da estimação dos preços de risco de mercado são: $\widehat{\lambda_{0}} \neq 0$ e $\widehat{\lambda_{1}} \neq 0$.

\subsection{3}

\section{Modelo gaussiano afim}

A partir dos parâmetros estimados na seção 3.2.2, é possível construir uma estrutura a termo da taxa de juros, estimada sob as hipóteses de nãoarbitragem. Desta forma, também é possível demonstrar que o preço dos títulos é exponencialmente afim no vetor das variáveis de estado:

$$
\ln P_{t}^{(n)}=A_{n}+B_{n}^{\prime} X_{t}+u_{t}^{(n)}
$$

Substituindo a equação (3-24) na equação (3-6), obtemos a seguinte relação:

$$
r x_{t+1}^{(n)}=A_{n-1}+B_{n-1}^{\prime} X_{t+1}+u_{t+1}^{(n-1)}-A_{n}-B_{n}^{\prime} X_{t}-u_{t}^{(n)}+A_{1}+B_{1}^{\prime} X_{t}+u_{t}^{(1)}
$$

A partir da combinação da equação (3-25) com a equação (3-18), e assumindo que $A_{1}=-\delta_{0}$ e $B_{1}=-\delta_{1}$, encontramos o seguinte sistema recursivo para os parâmetros de precificação dos títulos:

$$
A_{n}=A_{n-1}+B_{n-1}^{\prime}\left(\mu-\lambda_{0}\right)+\frac{1}{2}\left(B_{n-1}^{\prime} \Sigma B_{n-1}+\sigma^{2}\right)-\delta_{0}
$$




$$
B_{n}^{\prime}=B_{n-1}^{\prime}\left(\Phi-\lambda_{1}\right)-\delta_{1}^{\prime}
$$

$$
A_{0}=0=B_{0}^{\prime}
$$

e

$$
\beta^{(n) \prime}=B_{n}^{\prime}
$$

Adrian et al. (2013) demonstram que para resolução do sistema acima, podemos assumir que $\lambda_{0}$ e $\lambda_{1}$ são iguais a zero. Consequentemente, geramos os parâmetros de precificação dos títulos neutros ao risco e, posteriormente, construímos a estrutura a termo da taxa de juros neutra ao risco. Por fim, o prêmio de risco pode ser calculado como a diferença entre as taxas de rendimento neutras ao risco e as taxas ajustadas pelo modelo. 


\section{4}

\section{Resultados}

\section{1}

\section{Análise dos componentes principais}

Pela análise dos componentes principais da curva de juros, interpolada pelo modelo proposto por Svensson (1994), observa-se que os resultados obtidos para a ETTJ brasileira são semelhantes aos obtidos por Litterman e Scheinkman (1991) para a curva de juros americana, uma vez que os três primeiros componentes principais possuem poder explicativo sobre quase toda a variabilidade da curva de juros brasileira, conforme tabela 4.1 e figura 4.1. Posteriormente, relacionamos os três primeiros componentes principais à aspectos da curva de juros, representados nas figuras 4.2, 4.3 e 4.4.

Tabela 4.1: Análise dos componentes principais.

\begin{tabular}{|c|c|c|c|c|c|}
\hline & PC1 & PC2 & PC3 & PC4 & PC5 \\
\hline \hline Autovalor & 115.2284 & 4.3261 & 0.3737 & 0.0490 & 0.0206 \\
Proporção da Variância & 0.9602 & 0.0361 & 0.0031 & 0.0004 & 0.0002 \\
Variância Acumulada & 0.9602 & 0.9963 & 0.9994 & 0.9998 & 1.0000 \\
\hline
\end{tabular}

A tabela 4.1 apresenta os autovalores dos cinco primeiros componentes principais e a proporção na variância de cada componente principal. 
Figura 4.1: Análise dos coeficientes dos componentes principais.

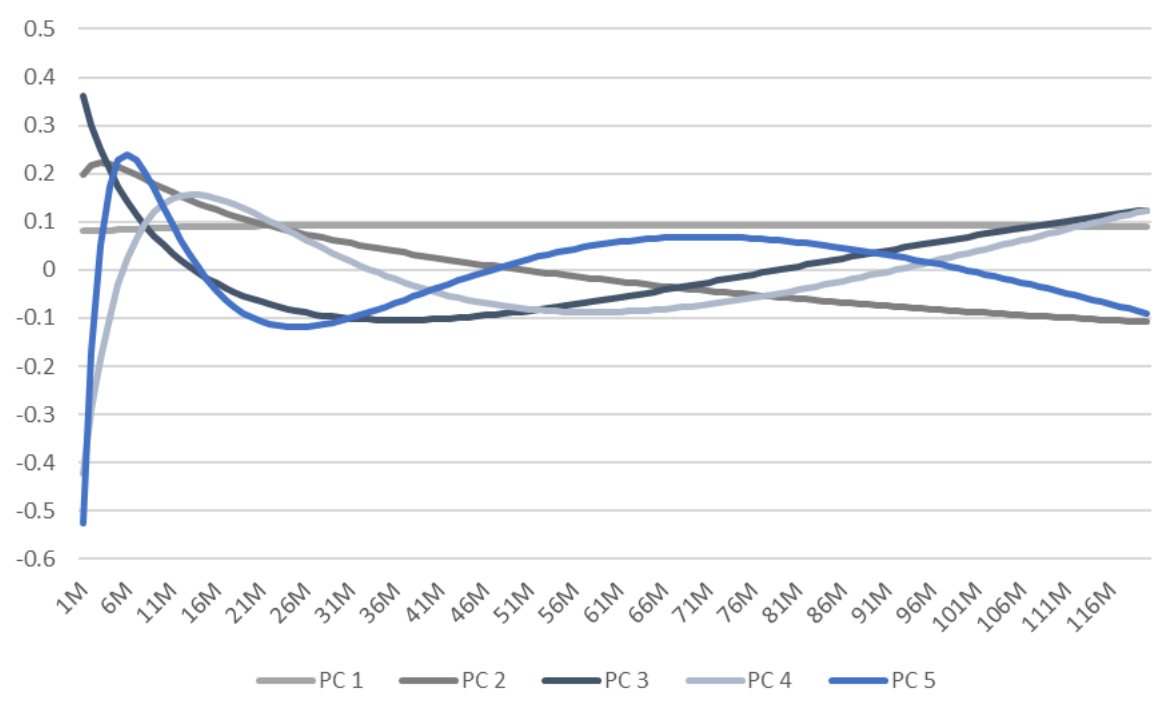

A figura 4.1 apresenta os coeficientes (factor loadings) dos cinco primeiros componentes principais para cada vértice da curva de juros entre 1 mês e 120 meses (10 anos).

Figura 4.2: Primeiro componente principal vs Nível da ETTJ.

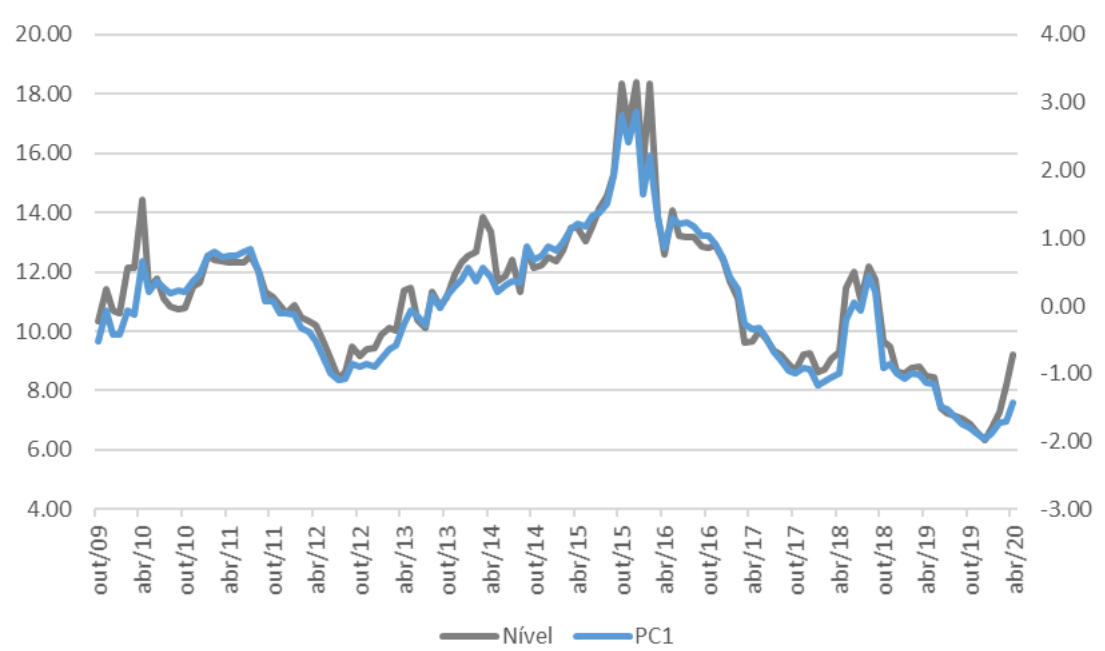

A figura 4.2 relaciona o primeiro componente principal ao nível da curva de juros, representado pela taxa de 120 meses (10 anos). 
Figura 4.3: Segundo componente principal vs Inclinação da ETTJ.

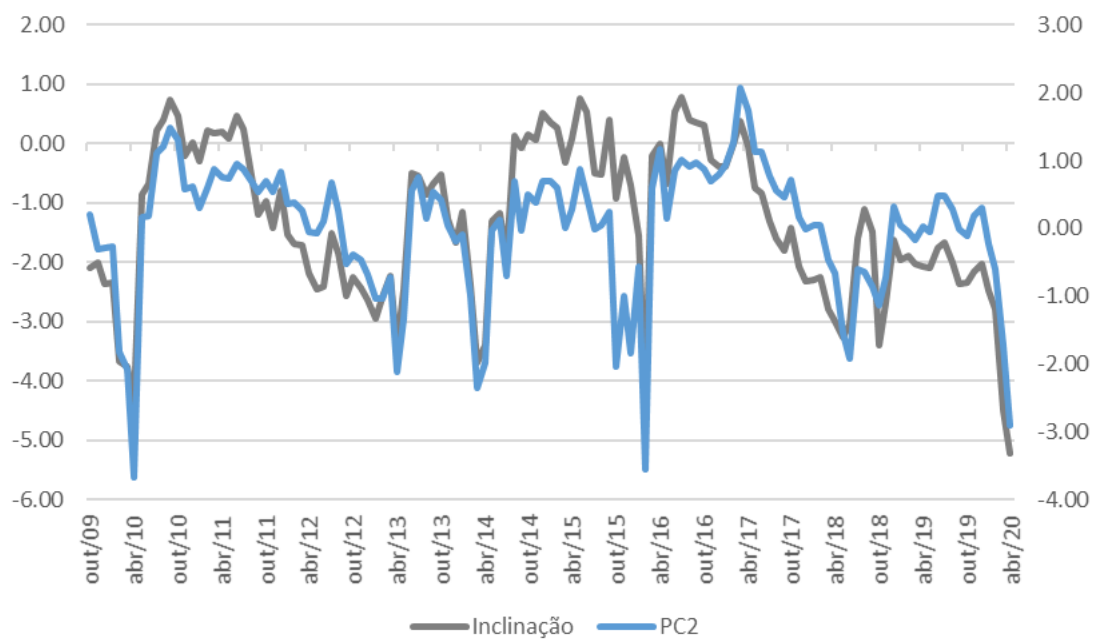

A figura 4.3 relaciona o segundo componente principal à inclinação da curva de juros, representada pelo spread entre as taxas de 120 meses (10 anos) e de 24 meses (2 anos)

Figura 4.4: Terceiro componente principal vs Curvatura da ETTJ.

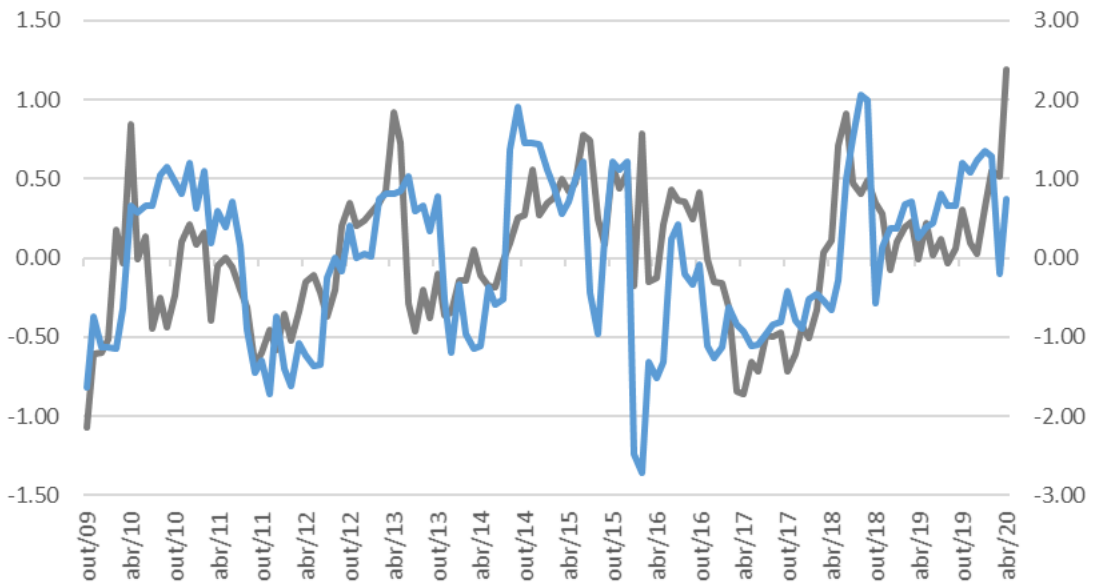

A figura 4.4 relaciona o terceiro componente principal à curvatura da curva de juros, representada pela butterfly spread, obtida pela compra das taxas de 120 meses (10 anos) e de 24 meses (2 anos), combinada com a venda de duas vezes a taxa de 60 meses ( 5 anos).

\section{2}

\section{Estimações dos excessos de retornos e preços de mercado do risco}

Conforme descrito no capítulo 3, o modelo proposto por Adrian et al. (2013) fundamenta-se em três etapas: i) estimação de um VAR (1) com os 
cinco primeiros componentes principais; ii) estimação por OLS dos excessos de retornos em uma constante, nos cinco fatores latentes defasados e nos resíduos de i); iii) por fim, estima-se por OLS os parâmetros do preço de risco de mercado a partir dos coeficientes dos resíduos estimados na regressão ii).

\subsection{1}

\section{Excessos de retornos}

Desta forma, extraímos os componentes principais para os yields de maturidades $n=3, \ldots, 120$ meses, e utilizando a taxa de $n=1$ como livre de risco, calculamos os excessos de retornos dos prazos $n=6,12,18,24,36$, 48, 60, 84 e 120 meses, que nos fornece uma análise em cross-section para nove maturidades. Os excessos dos retornos dos prazos foram estimados em função dos fatores latentes com uma defasagem e nos resíduos coletados do VAR(1), com os cinco primeiros componentes principais.

As estatísticas do $\operatorname{VAR}(1)$ se encontram no apêncice A e as estatísticas das regressões dos excessos de retornos se encontram no apêndice B deste trabalho. Em geral, os resultados são bastante robustos. Em todas as regressões de excesso de retorno, o $R^{2}$ ajustado fica próximo a 0.99. As estimações dos componentes principais também produziu resultados interessantes, sobretudo, na estimação do primeiro componente principal, que possui maior contribuição na variância, e produziu $R^{2}$ ajustado de aproximadamente 0.92 .

Adrian et al. (2013) demonstram que se você estimar os componentes principais e, posteriormente, tratá-los como variáveis observadas, elimina-se a necessidade de utilizar filtro de Kalman, como em outros modelos afim. A estimação da ETTJ pode ser feita de forma instantânea e com regressões lineares.

\subsection{2}

\section{Preços de mercado do risco}

Por fim, a partir das equações (3-22) e (3-23), podemos estimar $\lambda_{0}$ e $\lambda_{1}$, que são os preços de mercado do risco associados aos fatores latentes, ou seja, aos cinco primeiros componentes principais. $\lambda_{0}$ e $\lambda_{1}$ assumem a seguinte forma:

$$
\lambda_{0}=\left[\begin{array}{c}
\lambda_{01} \\
\lambda_{02} \\
\lambda_{03} \\
\lambda_{04} \\
\lambda_{05}
\end{array}\right] ; \lambda_{1}=\left[\begin{array}{ccccc}
\lambda_{111} & \lambda_{112} & \lambda_{113} & \lambda_{114} & \lambda_{115} \\
\lambda_{121} & \lambda_{122} & \lambda_{123} & \lambda_{124} & \lambda_{125} \\
\lambda_{131} & \lambda_{132} & \lambda_{133} & \lambda_{134} & \lambda_{135} \\
\lambda_{141} & \lambda_{142} & \lambda_{143} & \lambda_{144} & \lambda_{145} \\
\lambda_{151} & \lambda_{152} & \lambda_{153} & \lambda_{154} & \lambda_{155}
\end{array}\right]
$$


E, portanto, podemos recuperar os parâmetros para precificação da curva de juros a partir do sistema recursivo das equações (3-26; 3-27; 3-28; e 329). Para gerar os parâmetros da ETTJ neutra ao risco, podemos impor valores iguais a zero nas matrizes acima. A curva de juros gerada a partir da precificação neutra ao risco representa as expectativas dos agentes para os yields das diversas maturidades e a diferença entre as duas curvas é o prêmio de risco.

Os coeficientes estimados de $\widehat{\lambda_{0}}$ e $\widehat{\lambda_{1}}$ estão representados graficamente nas figuras 4.5 e 4.6 .

Figura 4.5: Parâmetros de $\widehat{\lambda_{0}}$.

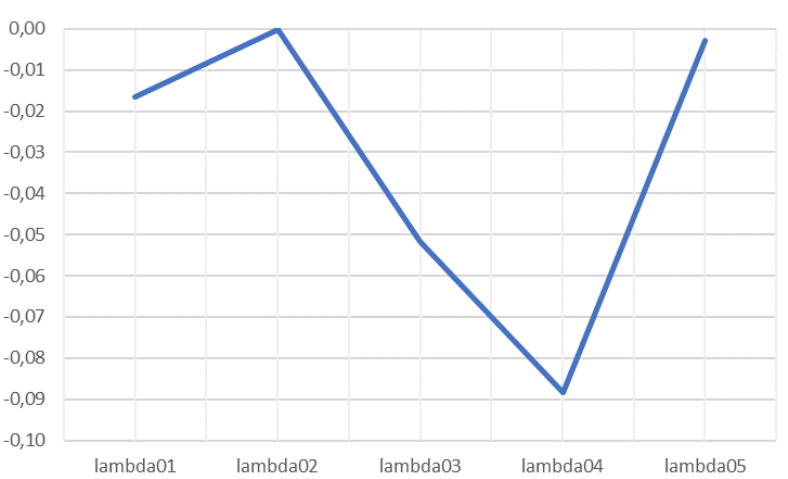

A figura 4.5 apresenta os parâmetros estimados para o preço de mercado do risco $\lambda_{0}$ do modelo de cinco fatores latentes. Os lambdas estão relacionados a cada um dos cinco componentes principais, em ordem crescente.

Figura 4.6: Parâmetros de $\widehat{\lambda_{1}}$.

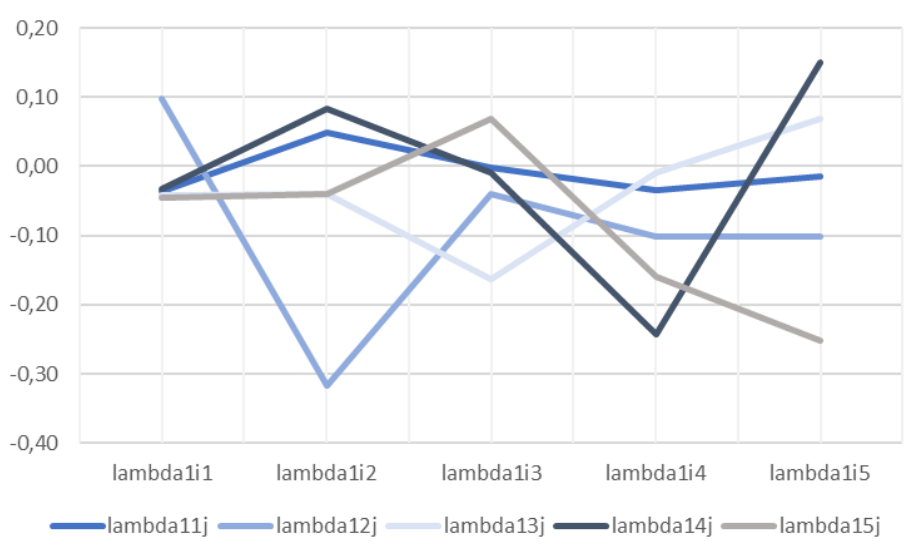

A figura 4.6 apresenta os parâmetros estimados para o preço de mercado do risco $\lambda_{1}$ do modelo de cinco fatores latentes. Os lambdas estão relacionados as combinações lineares dos cinco componentes principais, em ordem crescente. 


\section{3}

\section{Decomposição da curva de juros}

A partir das equações (3-26; 3-27, 3-28, 3-29) e das estimações realizadas nas seções 4.2 .1 e 4.2.2, pudemos recuperar a ETTJ com probabilidades reais, isto é, não-neutra ao risco. As figuras 4.7, 4.8 e 4.9 ilustram como os desvios entre as taxas mensais obtidas para as maturidades de 2 anos, 5 anos e 10 anos pelo modelo e as observadas são substancialmente pequenos. A maior diferença absoluta entre as medidas ficou em $0.16 \%$, a média dos erros analisados é de $0.01 \%$ e desvio padrão de $0.03 \%$.

Figura 4.7: Yield de 2 anos estimado vs observado.

$18.00 \%$

$16.00 \%$

.

$+2$

$14.00 \%$

$12.00 \%$

$10.00 \%$

$8.00 \%$

$6.00 \%$

$4.00 \%$

$2.00 \%$

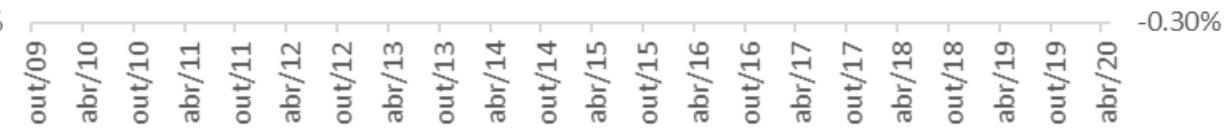

2Y observada

$-2 Y$ estimado

------Desvios

A figura 4.7 apresenta a estimação do yield de 2 anos e compara com o dado observado. No eixo da direita, apresento os desvios entre o estimado e o observado. 
Figura 4.8: Yield de 5 anos estimado vs observado.

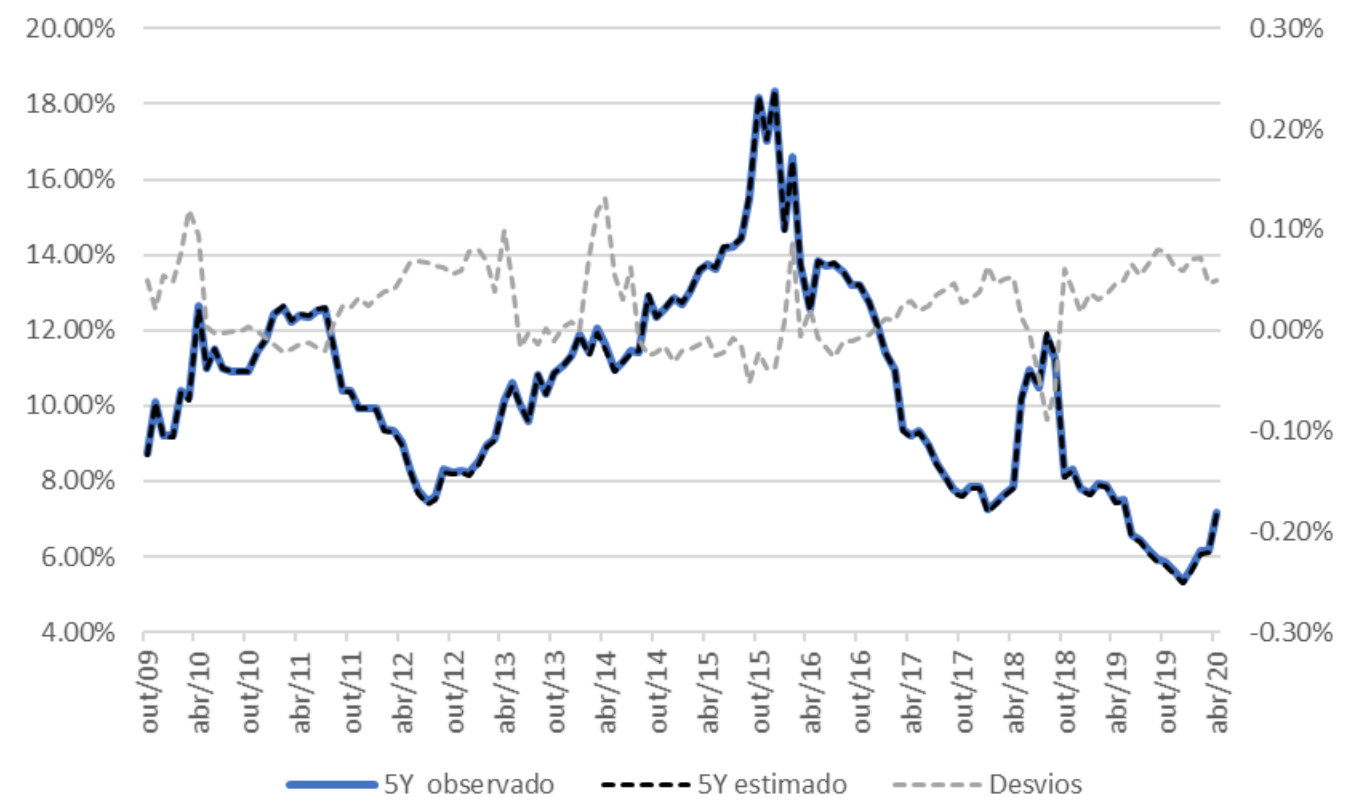

A figura 4.8 apresenta a estimação do yield de 5 anos e compara com o dado observado. No eixo da direita, apresento os desvios entre o estimado e o observado.

Figura 4.9: Yield de 10 anos estimado vs observado.

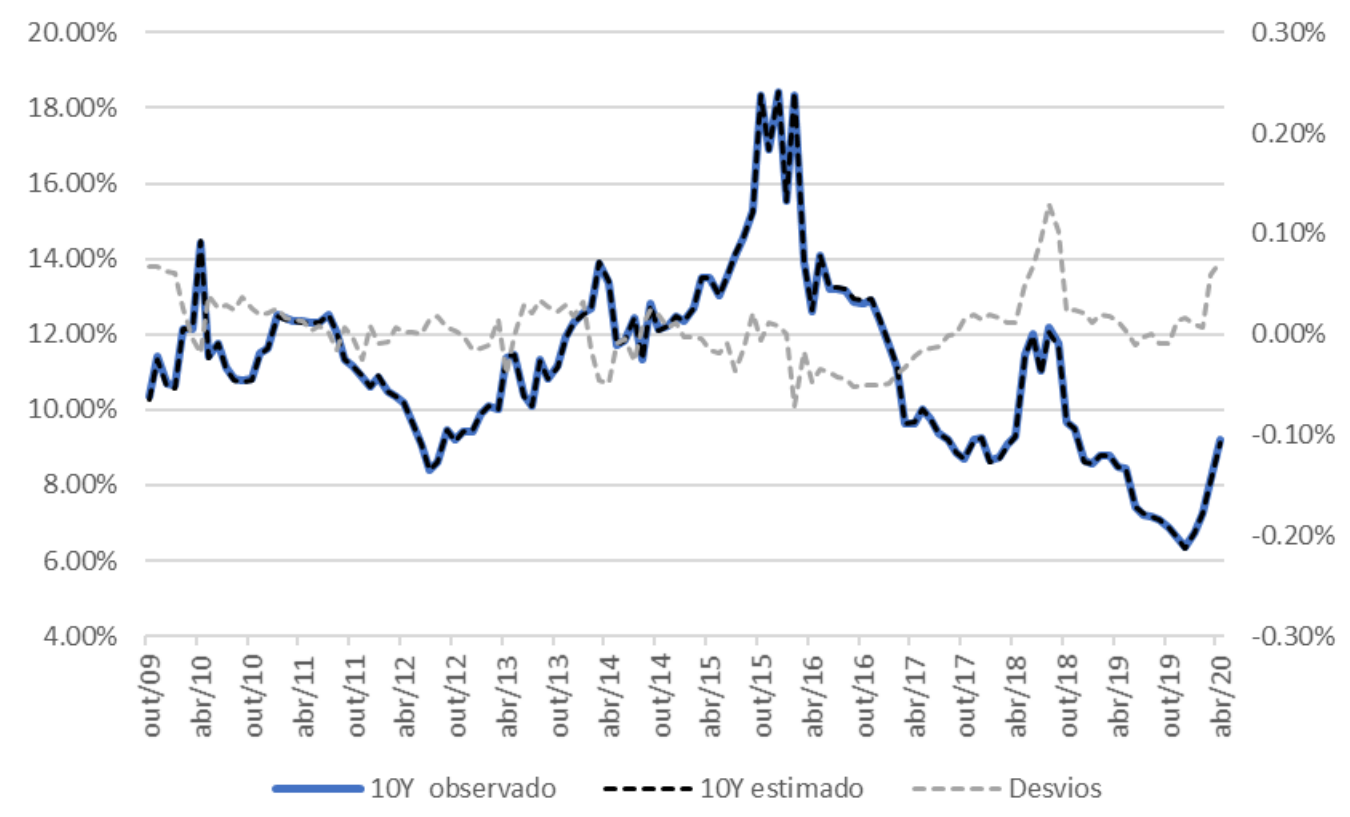

A figura 4.9 apresenta a estimação do yield de 10 anos e compara com o dado observado. No eixo da direita, apresento os desvios entre o estimado e o observado. 
De forma análoga, ao impormos $\lambda_{0}=0=\lambda_{1}$, podemos recuperar a ETTJ neutra ao risco. A estimação neutra ao risco pode ser interpretada como a expectativa dos agentes quanto às taxas futuras. Nas figuras 4.10, 4.11 e 4.12, comparamos as taxas de retorno neutras ao risco de 2 anos, 5 anos e 10 anos com a ETTJ de probabilidades reais.

A diferença entre as duas curvas é interpretada como prêmio de risco variante no tempo. Os prêmios médios para os vértices de 2, 5 e 10 anos, durante período analisado, são de $0.65 \%$, 1.86\% e 3.30\%, respectivamente. Nos gráficos 4.13, 4.14 e 4.15, ilustramos o comportamento do prêmio de risco estimado para cada maturidade com mais ou menos um desvio padrão.

É possível verificar, em primeiro lugar, que o nível médio do prêmio de risco e o desvio padrão aumentam conforme se aumenta a maturidade. Entretanto, verifica-se que o incremento marginal nos desvios padrões é descrescente, ou seja, o aumento do desvio padrão de um vértice para outro é maior nas maturidades mais curtas.

Figura 4.10: Yield de 2 anos vs neutro ao risco.

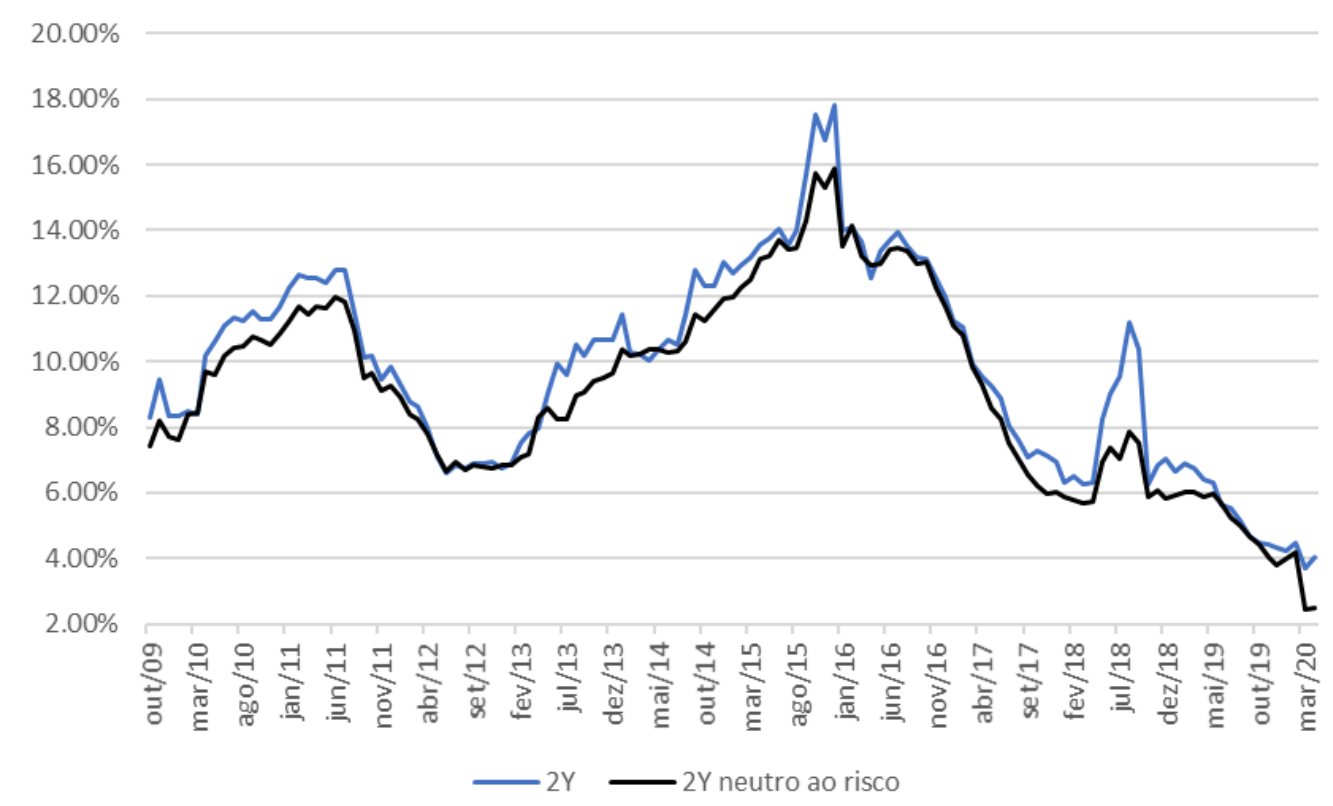

A figura 4.10 apresenta as estimaçãos do yield de 2 anos com probabilidades reais e neutra ao risco. 
Figura 4.11: Yield de 5 anos vs neutro ao risco.

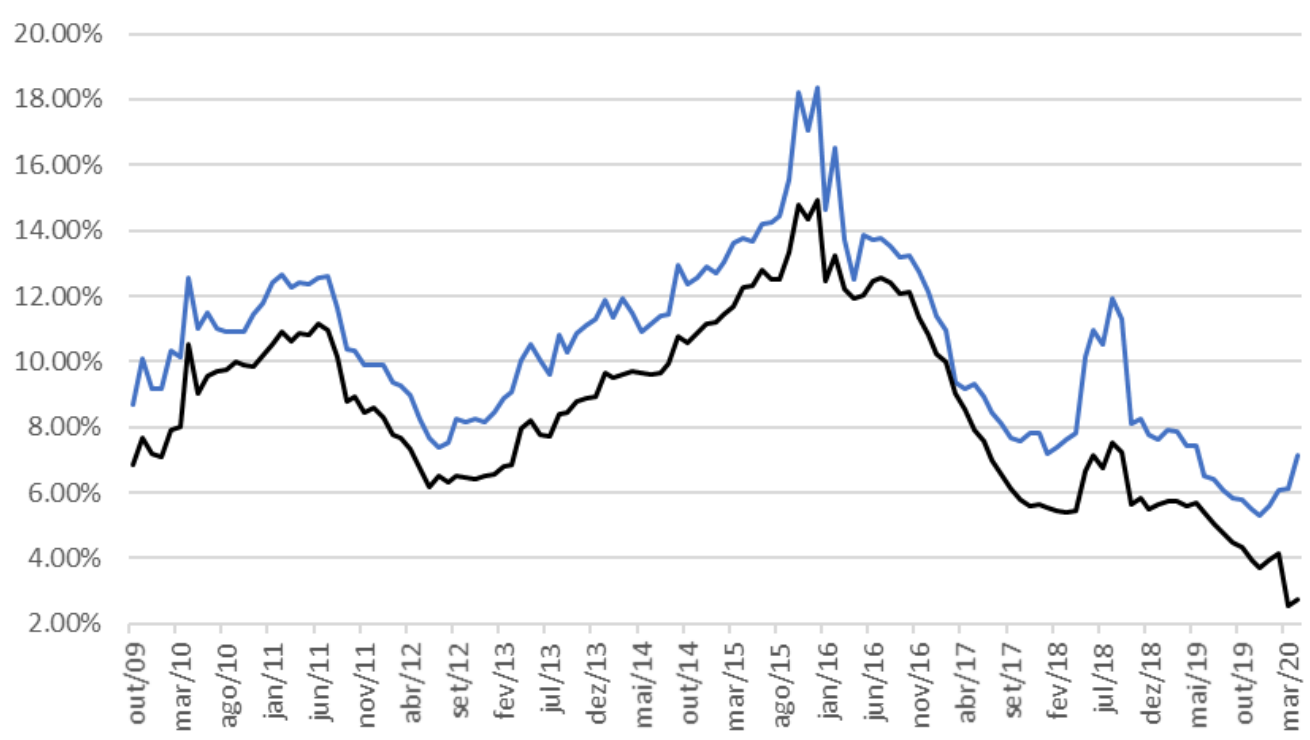

$-5 Y-5 Y$ neutro ao risco

A figura 4.11 apresenta as estimaçãos do yield de 5 anos com probabilidades reais e neutra ao risco.

Figura 4.12: Yield de 10 anos vs neutro ao risco.

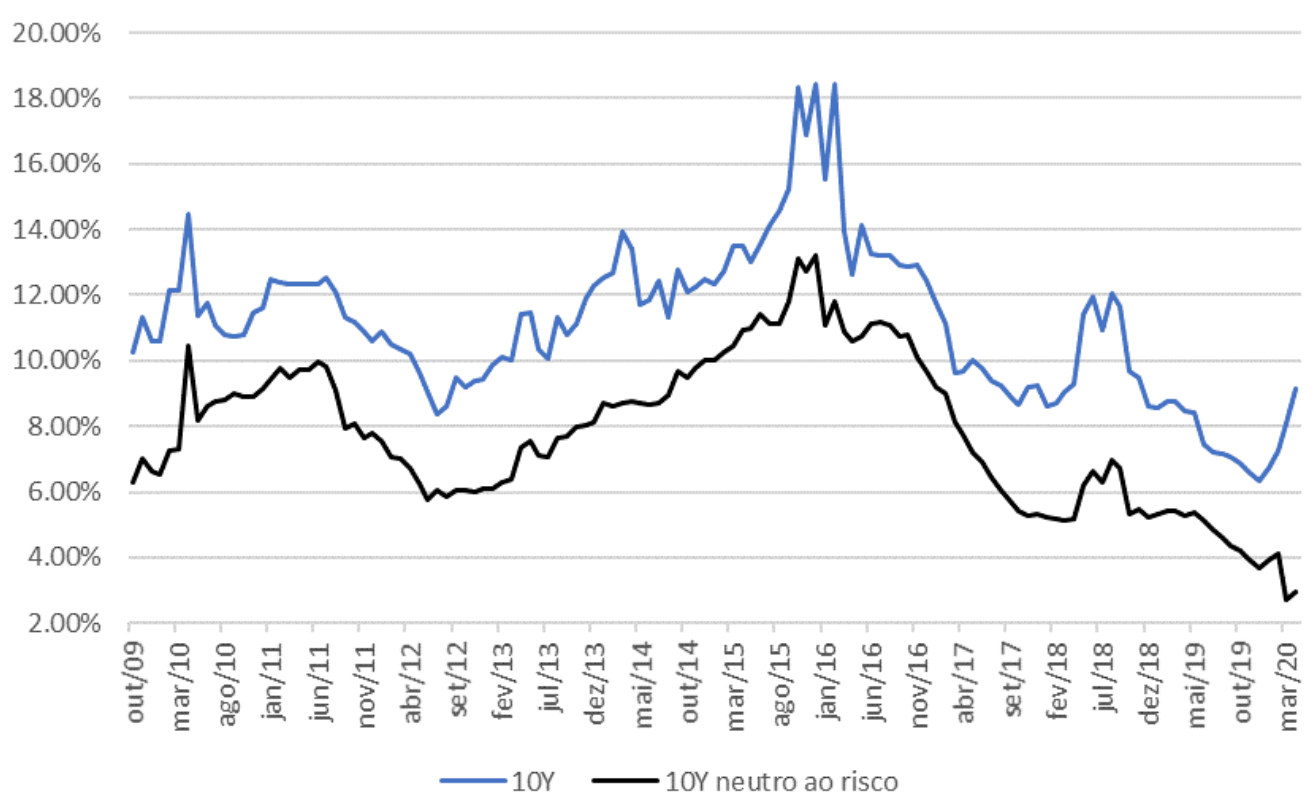

A figura 4.12 apresenta as estimaçãos do yield de 10 anos com probabilidades reais e neutra ao risco. 
Figura 4.13: Estimação do prêmio de risco de 2 anos.

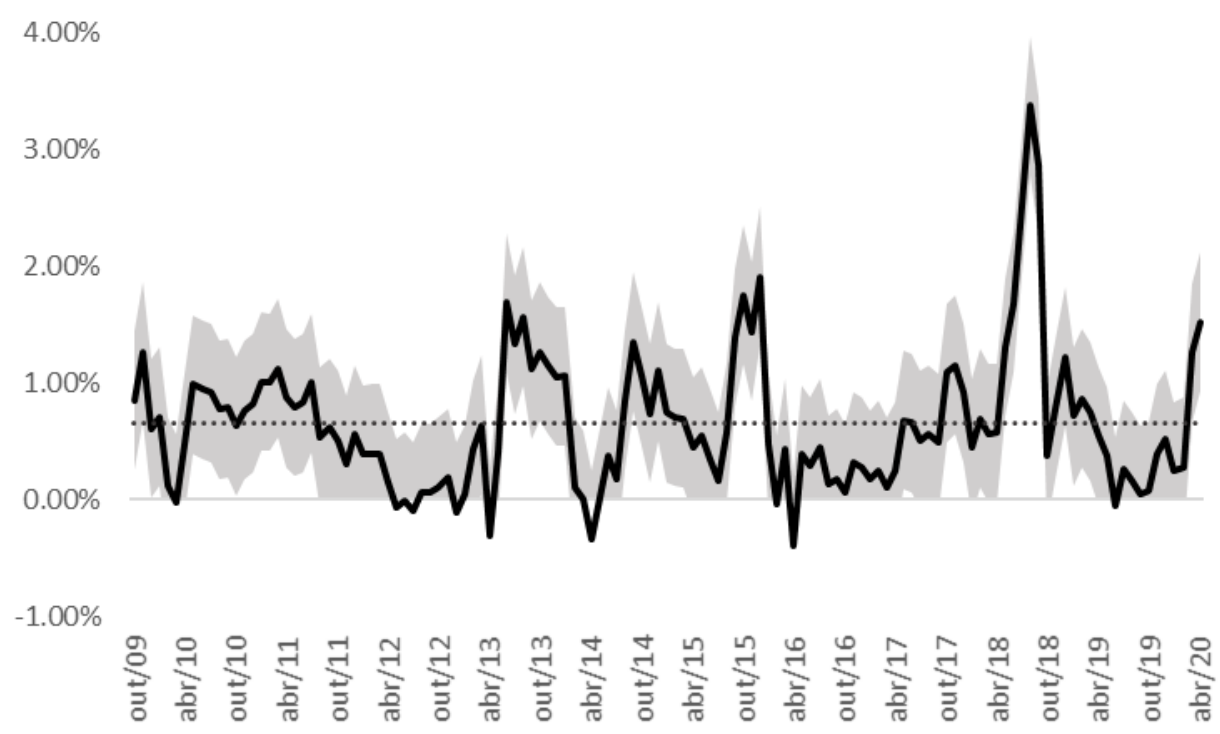

A figura 4.13 apresenta o prêmio de risco estimado para a maturidade de 2 anos. A média e o desvio-padrão amostral são, respectivamente, $0.65 \%$ e $0.59 \%$.

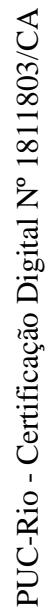

Figura 4.14: Estimação do prêmio de risco de 5 anos.

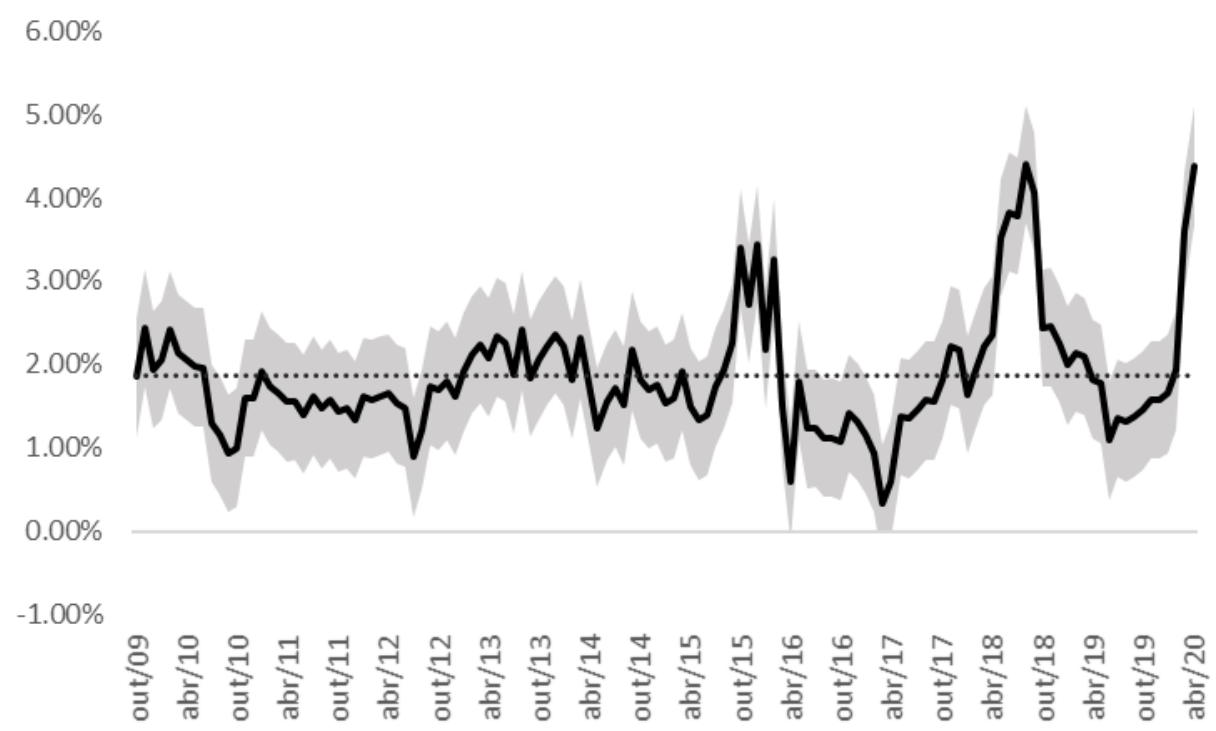

A figura 4.14 apresenta o prêmio de risco estimado para a maturidade de 5 anos. A média e o desvio-padrão amostral são, respectivamente, 1.86\% e $0.71 \%$. 
Figura 4.15: Estimação do prêmio de risco de 10 anos.

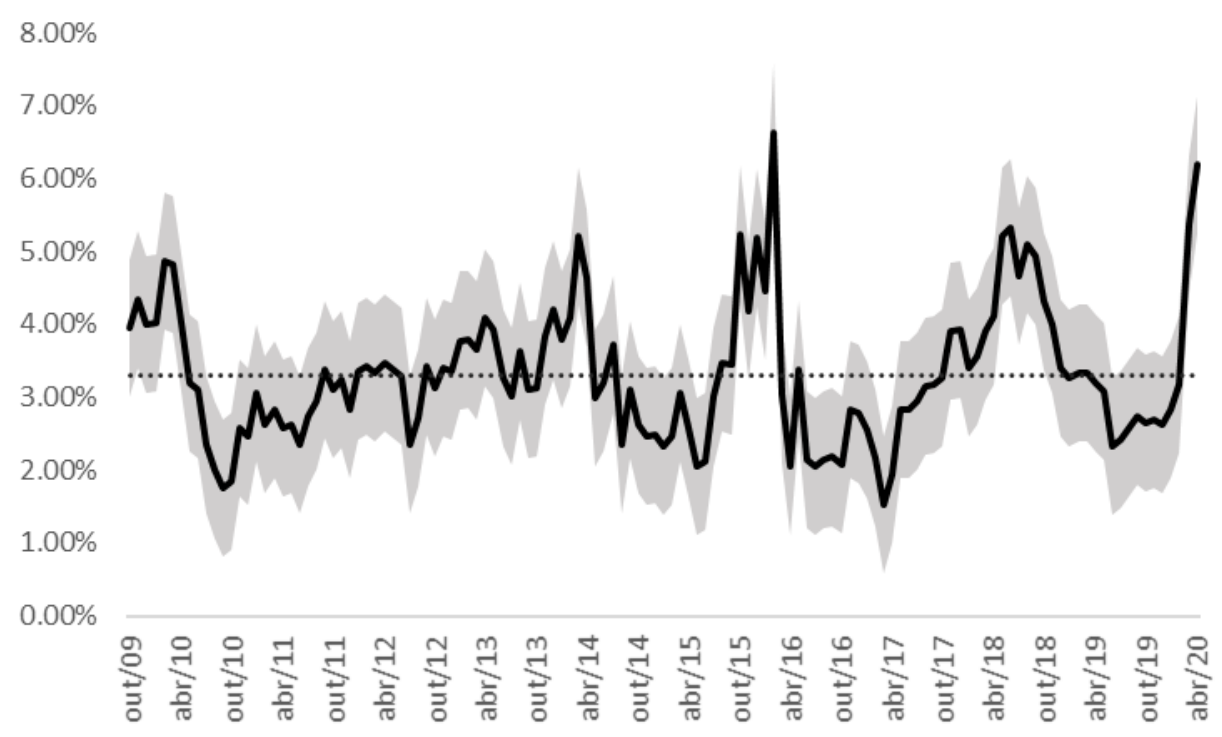

A figura 4.15 apresenta o prêmio de risco estimado para a maturidade de 10 anos. A média e o desvio-padrão amostral são, respectivamente, $3.30 \%$ e $0.94 \%$.

Os dados amostrais se iniciam em outubro de 2009, período em que os países se recuperavam da forte crise financeira que assolou o mundo em 2007 e 2008. Com a forte contração das condições financeiras internacionais durante este período, é possível creditar a alta dos prêmios de risco no início destas séries às instabilidades que os países ainda lidavam, principalmente os países emergentes.

Com a forte recuperação no pós-crise, em especial das economias emergentes $^{1}$, observa-se uma forte redução do prêmio de risco ao longo de 2010, principalmente nos prazos mais longos. No segundo semestre de 2013 e início do primeiro semetre de 2014, observa-se forte aceleração dos prêmios de risco, principalmente nas maturidades mais longas. Estes movimentos podem ser explicados pelo Taper Tantrum, fenômeno resultante da sinalização do Federal Reserve de que poderia reduzir o programa de compra de ativos (Quantitative Easing), provocando forte pressão sobre os yields dos títulos do Tesouro americano e aperto das condições financeiras globais.

O ano de 2015, início do segundo mandato de Dilma Rousseff, dava sinais de esgotamento do modelo adotado nos 4 anos primeiros anos de mandato. Com forte expansão fiscal nos anos anteriores, a economia brasileira dava sinais de retração em 2015. Com dificuldades de emplacar um ajuste fiscal, o governo anunciou revisões na meta fiscal ao longo do ano. Na iminência de um colapso fiscal, o mercado precificou forte alta nas expectativas futuras para as taxas

\footnotetext{
${ }^{1}$ De acordo com os dados do IBGE, o Brasil registrou crescimento de $7.5 \%$ em 2010.
} 
de juros e, principalmente, forte alta nos prêmios de risco. Além disto, o Brasil perdeu o grau de investimento e encerrou 2015 com alta de 10,67\% na inflação acumulada em 12 meses.

No primeiro semestre de 2016, é possível observar forte retração das expectativas futuras das taxas de juros e dos prêmios de risco. Este movimento pode ser justificado pelo avanço do processo de impeachment que culminou na saída de Dilma Rousseff e assunção de Michel Temer à presidência do Brasil, sob discurso reformista e na defesa de um ajuste fiscal. No final de 2016, com a aprovação da PEC (Proposta de Emenda Constitucional) do teto de gastos, que limita o crescimento das despesas do governo, as séries de prêmios de risco fizeram ponto de mínimo, em um contexto que o mercado apostava na aprovação de outra reformas durante o governo Temer. Entretanto, no ano seguinte é possível notar uma aceleração no prêmio de risco a partir de maio, em função do evento conhecido como "Joesley Day", em que foram liberadas gravações sobre uma suposta compra de silêncio, entre o empresário Joesley Batista e o ex-presidente Michel Temer. O mercado interpretou este evento como o fim da agenda de reformas do governo.

O ano de 2018, marcado pelas eleições presidenciais no Brasil, se iniciou com forte aperto das condições financeiras globais e fim do interregno benigno. Esta redução da liquidez global fez o Banco Central do Brasil não realizar o corte de juros na reunião de maio, como havia sinalizado na reunião anterior, gerando forte volatilidade nos preços dos ativos brasileiros por conta do ruído na comunicação da autoridade monetária. A alta do Dólar em relação ao Real somada ao movimento nos preços das commodities fez os preços dos combustíveis registrarem forte alta no mercado doméstico. Isto culminou na greve dos caminhoneiros, que teve impactos relevantes sobre atividade e inflação. Essa deterioração dos preços dos ativos brasileiros e, consequentemente, dos prêmios de risco, se acentuaram em meio à um cenário eleitoral conturbado. Posteriormente, com a vitória do candidato Jair Bolsonaro, com defesa de uma agenda econômica liberal e reformista, os prêmios de risco se reduziram até o fim do ano. Em 2019 foi aprovada a reforma da previdência, que promoveu nova queda nas expectativas futuras para as taxas de juros e quedas nos prêmios de risco.

Por fim, no início de 2020 pode-se notar forte elevação do prêmio de risco, em um momento em que as expectativas para as taxas de juros futuras recuavam. Isto pode ser explicado pelo choque sofrido nas economias globais em função do novo coronavírus. A resposta da maior parte dos Bancos Centrais foi de aumentar os estímulos monetários em um momento em que as condições financeiras foram apertadas por conta da alta incerteza em torno 
desta pandemia, e os governos realizaram expansão dos gastos públicos.

\section{4}

\section{Previsões fora da amostra}

O modelo proposto por Adrian et al. (2013) também nos permite gerar previsões fora da amostra.

A partir do VAR(1) estimado, podemos gerar previsões para os componentes principais. Com os componentes principais projetados, calculamos um novo VAR(1) com os componentes principais $t$ períodos a frente e coletamos os seus resíduos. Posteriormente, realizamos as previsões dos excessos de retornos $t$ períodos a frente, a partir dos resíduos coletados e dos componentes principais projetados. Com a matriz de excessos de retornos, conseguimos a partir do sistema recursivo, apresentado no capítulo anterior, recuperar a ETTJ estimada e projetada $t$ períodos a frente. Nesta simulação, realizamos a previsão de $t=6$ períodos para as taxas de 2 anos, 5 anos e 10 anos, conforme figuras $4.16,4.17$ e 4.18 .

Figura 4.16: Previsão fora da amostra 2 anos: modelo vs random walk.

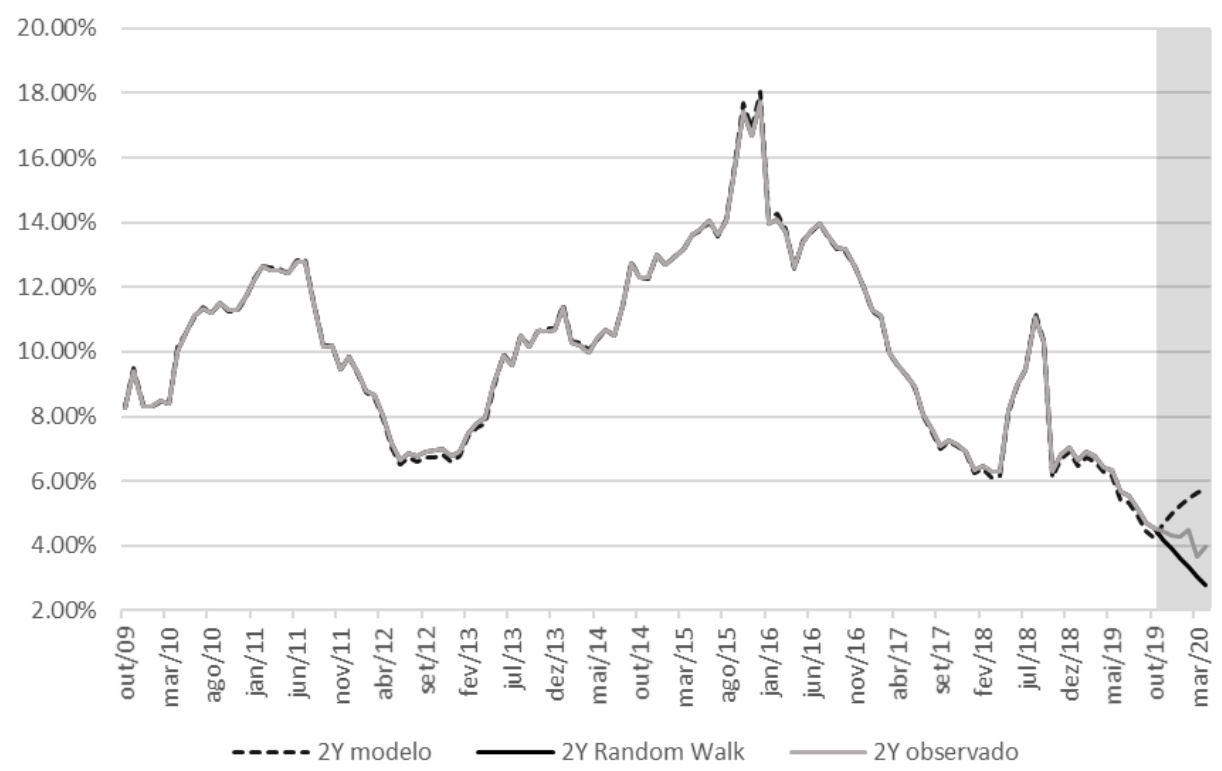

A figura 4.16 apresenta o comparativo das previsões fora da amostra em seis períodos a frente para a maturidade de 2 anos, geradas pelo modelo afim e por random walk. 
Figura 4.17: Previsão fora da amostra 5 anos: modelo vs random walk.

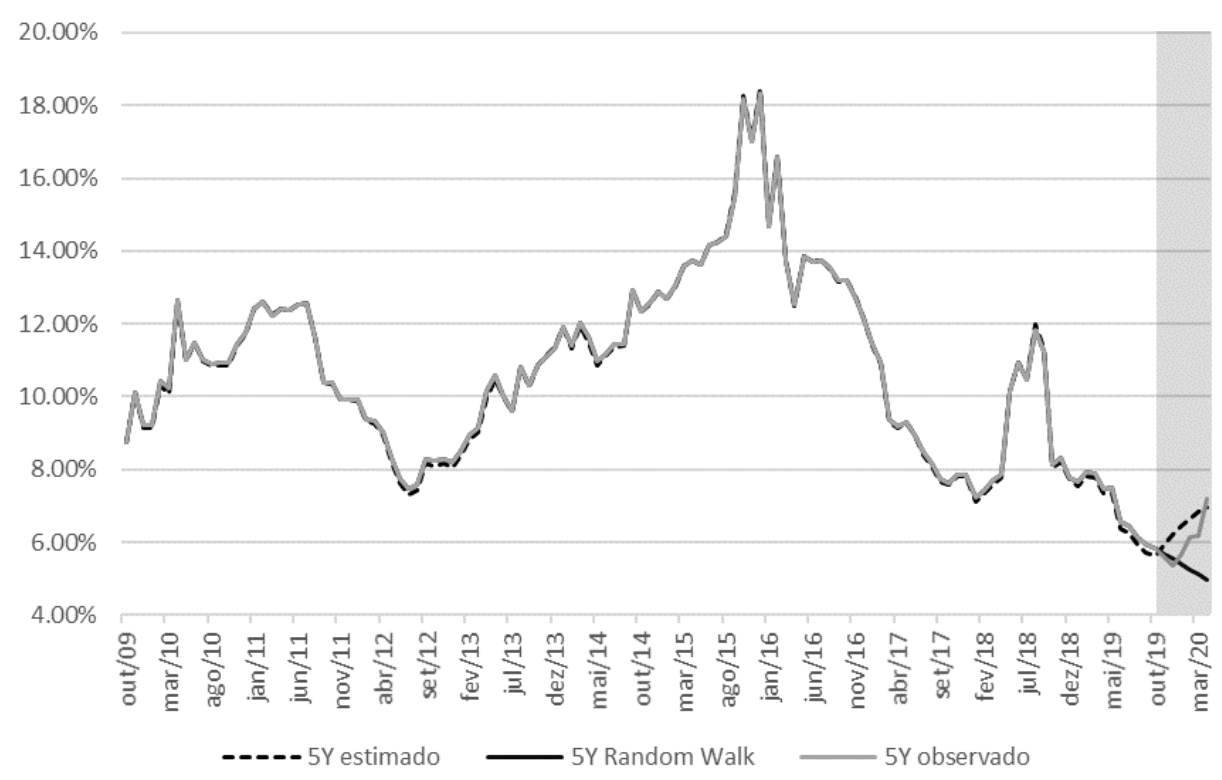

A figura 4.17 apresenta o comparativo das previsões fora da amostra em seis períodos a frente para a maturidade de 5 anos, geradas pelo modelo afim e por random walk.

Figura 4.18: Previsão fora da amostra 10 anos: modelo vs random walk.

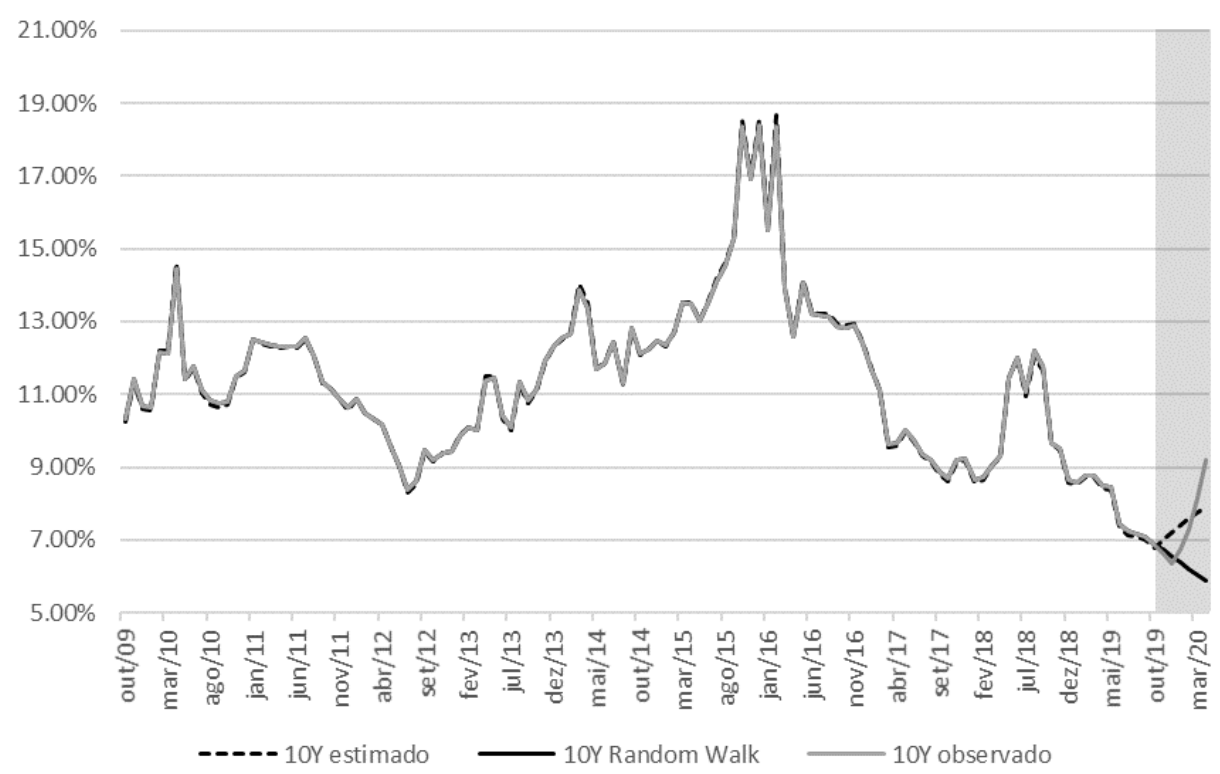

A figura 4.18 apresenta o comparativo das previsões fora da amostra em seis períodos a frente para a maturidade de 10 anos, geradas pelo modelo afim e por random walk. 
É possível verificar descasamentos entre as previsões geradas pelo modelo e os dados reais. Esta limitação se deve ao fato de que o modelo considera apenas as variáveis latentes para explicar os movimentos da curva de juros. Portanto, o modelo perde informações ao não considerar as variáveis macroeconômicas que possuem impacto direto sobre os movimentos da ETTJ.

Realizamos um comparativo entre as previsões geradas pelo modelo contra previsões geradas por um modelo de passeio aleatório (random walk). Utilizamos a medida de Erro Quadrático Médio (EQM) das variações das taxas para avaliar qual modelo possui melhor performance. Os resultados sugerem que o modelo de cinco variáveis latentes apresentou performance ligeiramente superior às estimações por passeio aleatório, conforme tabela 4.2.

Tabela 4.2: EQM dos modelos

\begin{tabular}{|c|c|c|}
\hline Maturidade & Modelo Afim & Random Walk \\
\hline \hline 2 anos & $0.41 \%$ & $0.40 \%$ \\
5 anos & $0.32 \%$ & $0.48 \%$ \\
10 anos & $0.37 \%$ & $0.56 \%$ \\
\hline
\end{tabular}

A tabela 4.2 apresenta as comparações das previsões fora da amostra gerada pelos modelos afim e random walk. Em geral, quanto menor for o EQM, melhores são as previsões geradas pelo modelo. 


\section{5}

\section{Conclusão}

O objetivo deste trabalho foi construir uma série histórica para o prêmio de risco variante no tempo, a partir de um modelo gaussiano afim de cinco variáveis latentes para o período compreendido entre outubro de 2009 e abril de 2020.

Os resultados obtidos pela estimação da curva de juros são bastante interessantes, e o modelo possui boa aderência entre a ETTJ estimada e a observada, o que é uma característica dos modelos do tipo afim. Apesar do período final da amostra ser de meses em que a economia global sofreu com o choque provocado pela Covid-19, o modelo proposto por Adrian et al. (2013) apresentou boa performance nas previsões fora da amostra, ainda mais se comparado às estimativas geradas por um modelo de passeio aleatório.

Uma limitação deste modelo de não arbitragem é que utiliza apenas variáveis latentes, ou seja, variáveis não observáveis para explicar as dinâmicas da curva de juros. Este modelo ignora as relações que as taxas de juros possuem com as variáveis macroeconômicas, como medidas de atividade e inflação. Outro ponto, é que as estimações para as relações das variáveis latentes e dos excessos de retornos são lineares, isto é, não consideram a possibilidade de quebras estruturais ou mudanças de regimes.

Apesar do modelo não considerar variáveis macroeconômicas, é possível verificar forte aceleração do prêmio de risco em momentos de aperto das condições financeiras ou de deteriorações fiscais, como no período compreendido entre 2013 e 2015. Ainda, as séries de prêmios de risco de maturidades mais longas fizeram pontos de mínimos em período marcado pela aprovação da PEC do teto de gastos, considerada como a âncora fiscal do país.

Pesquisas futuras que estendam a aplicação do modelo para estimação do prêmio de risco de inflação ou de crédito, ou que incorporem uma maior amostra de dados, podem contribuir para uma maior robustez dos resultados do modelo. Por fim, o estudo do prêmio de risco é de extrema importância na literatura de macroeconomia e finanças, dada a sua relevância nas decisões de alocação de capital e/ou formulação de políticas econômicas. 


\section{Bibliografia}

Adrian, T., Crump, R. K. \& Moench, E. (2013). Pricing the term structure with linear regressions. Journal of Financial Economics, 110(1), 110138.

Brito, R. D., Duarte, A. J. \& Guillén, O. T. (2003). O prêmio pela maturidade na estrutura a termo das taxas de juros brasileiras. BCB Working Paper Series, (72).

Campbell, J. Y. \& Shiller, R. J. (1991). Yield spreads and interest rate movements: A bird's eye view. The Review of Economic Studies, 58(3), 495-514.

Cochrane, J. H. \& Piazzesi, M. (2005). Bond risk premia. American Economic Review, 95(1), 138-160.

Cochrane, J. H. \& Piazzesi, M. (2009). Decomposing the yield curve, Em Afa 2010 atlanta meetings paper.

Cox, J. C., Ingersoll Jr, J. E. \& Ross, S. A. (1985). An intertemporal general equilibrium model of asset prices. Econometrica: Journal of the Econometric Society, 363-384.

Crump, R. K., Eusepi, S. \& Moench, E. (2016). The term structure of expectations and bond yields. FRB of NY Staff Report, (775).

Dai, Q. \& Singleton, K. J. (2000). Specification analysis of affine term structure models. The journal of finance, 55 (5), 1943-1978.

Duffee, G. R. (2002). Term premia and interest rate forecasts in affine models. The Journal of Finance, 57(1), 405-443.

Fama, E. F. \& Bliss, R. R. (1987). The information in long-maturity forward rates. The American Economic Review, 680-692.

Fisher, I. (1896). Appreciation and interest: A study of the influence of monetary appreciation and depreciation on the rate of interest with applications to the bimetallic controversy and the theory of interest (Vol. 11). American economic association.

Kim, D. H. \& Orphanides, A. (2005). Term structure estimation with survey data on interest rate forecasts. The Journal of Financial and Quantitative Analysis, 47(1), 241-272. 
Kim, D. H. \& Wright, J. H. (2005). An arbitrage-free three-factor term structure model and the recent behavior of long-term yields and distanthorizon forward rates. FED Working Paper, (2005-33).

Litterman, R. \& Scheinkman, J. (1991). Common factors affecting bond returns. Journal of fixed income, 1(1), 54-61.

Piazzesi, M. \& Swanson, E. T. (2008). Futures prices as risk-adjusted forecasts of monetary policy. Journal of Monetary Economics, 55(4), 677-691.

Shousha, S. (2008). Estrutura a termo da taxa de juros e dinâmica macroeconômica no brasil. Banco Nacional de Desenvolvimento Econômico e Social.

Svensson, L. E. (1995). Estimating forward interest rates with the extended nelson \& siegel method. Sveriges Riksbank Quarterly Review, 3(1), 1326.

Tabak, B. M. \& de Andrade, S. C. (2003). Testing the expectations hypothesis in the brazilian term structure of interest rates. Brazilian Review of Finance, 1 (1), 19-43.

Wright, J. H. (2011). Term premia and inflation uncertainty: Empirical evidence from an international panel dataset. American Economic Review, $101(4), 1514-34$. 


\section{A}

\section{$\operatorname{VAR}(1)$ dos componentes principais}

A tabela A.1 apresenta os resultados obtidos no VAR(1) dos cinco primeiros componentes principais. Os p-valores são apresentados entre parênteses e as estatísticas $t$ são apresentadas entre colchetes.

\begin{tabular}{cccccc} 
& $\mathrm{X} 1$ & $\mathrm{X} 2$ & $\mathrm{X} 3$ & $\mathrm{X} 4$ & $\mathrm{X} 5$ \\
\hline $\mathrm{N} 1(-1)$ & 0.965301 & 0.141316 & -0.111606 & -0.017378 & -0.036885 \\
& $(0.02632)$ & $(0.06905)$ & $(0.05688)$ & $(0.06229)$ & $(0.06382)$ \\
& {$[36.6731]$} & {$[2.04644]$} & {$[-1.96214]$} & {$[-0.27899]$} & {$[-0.57798]$} \\
X2(-1) & 0.035634 & 0.670340 & -0.098772 & -0.055928 & -0.065150 \\
& $(0.02708)$ & $(0.07105)$ & $(0.05853)$ & $(0.06409)$ & $(0.06566)$ \\
& {$[1.31570]$} & {$[9.43433]$} & {$[-1.68766]$} & {$[-0.87261]$} & {$[-0.99217]$} \\
X3(-1) & 0.005029 & 0.016747 & 0.759487 & -0.017565 & 0.101095 \\
& $(0.02614)$ & $(0.06858)$ & $(0.05649)$ & $(0.06186)$ & $(0.06338)$ \\
& {$[0.19237]$} & {$[0.24419]$} & {$[13.4448]$} & {$[-0.28394]$} & {$[1.59510]$} \\
X4(-1) & -0.029944 & -0.075482 & -0.089775 & 0.706561 & -0.044311 \\
& $(0.02609)$ & $(0.06844)$ & $(0.05637)$ & $(0.06173)$ & $(0.06325)$ \\
& {$[-1.14785]$} & {$[-1.10293]$} & {$[-1.59256]$} & {$[11.4456]$} & {$[-0.70062]$} \\
X5(-1) & -0.011803 & -0.080916 & 0.014045 & 0.017335 & 0.740711 \\
& $(0.02713)$ & $(0.07116)$ & $(0.05862)$ & $(0.06419)$ & $(0.06576)$ \\
& {$[-0.43512]$} & {$[-1.13706]$} & {$[0.23961]$} & {$[0.27005]$} & {$[11.2630]$} \\
& & & & & \\
Adj. R-squared & 0.914839 & 0.414950 & 0.594655 & 0.504355 & 0.498250 \\
& -0.007759 & -0.020247 & 0.021513 & -0.017863 & 0.025982 \\
& $(0.02620)$ & $(0.06872)$ & $(0.05661)$ & $(0.06199)$ & $(0.06351)$ \\
& {$[-0.29620]$} & {$[-0.29461]$} & {$[0.38004]$} & {$[-0.28815]$} & {$[0.40909]$} \\
\hline \multirow{2}{*}{ C } & 0.918245 & 0.438352 & 0.610869 & 0.524181 & 0.518320 \\
& & & & &
\end{tabular}

Tabela A.1: $\operatorname{VAR}(1)$ dos cinco componentes principais. 
B

\section{Regressões dos excessos de retornos}

As tabelas B.1 a B.9 apresentam os resultados das estimações dos excessos de retorno de 6 meses, 12 meses, 18 meses, 24 meses, 36 meses, 48 meses, 60 meses, 84 meses e 120 meses, respectivamente.

\begin{tabular}{crrrr} 
Variable & Coefficient & Std. Error & t-Statistic & Prob. \\
\hline C & $8.27 E-07$ & $9.52 E-08$ & 8.684771 & 0.0000 \\
RESID01 & -0.000110 & $7.87 E-07$ & -139.9367 & 0.0000 \\
RESID02 & $-5.59 E-05$ & $2.62 E-07$ & -213.8700 & 0.0000 \\
RESID03 & $1.34 E-05$ & $2.59 E-07$ & 51.85530 & 0.0000 \\
RESID04 & $1.48 E-06$ & $1.69 E-07$ & 8.777848 & 0.0000 \\
RESID05 & $-4.10 E-06$ & $1.63 E-07$ & -25.23800 & 0.0000 \\
X1(-1) & $-1.95 E-06$ & $9.56 E-08$ & -20.40750 & 0.0000 \\
X2(-1) & $1.24 E-05$ & $9.84 E-08$ & 126.0226 & 0.0000 \\
X3(-1) & $1.58 E-07$ & $9.50 E-08$ & 1.662518 & 0.0991 \\
X4(-1) & $9.80 E-06$ & $9.48 E-08$ & 103.4190 & 0.0000 \\
X5(-1) & $9.82 E-06$ & $9.86 E-08$ & 99.58771 & 0.0000 \\
\hline & & & & \\
R-squared & 0.999148 & & &
\end{tabular}

Tabela B.1: Regressão do excesso de retorno do yield de 6 meses. 


\begin{tabular}{crrrr} 
Variable & Coefficient & Std. Error & t-Statistic & Prob. \\
\hline C & $5.22 E-06$ & $1.56 E-07$ & 33.42933 & 0.0000 \\
RESID01 & -0.000258 & $1.29 E-06$ & -199.9027 & 0.0000 \\
RESID02 & $-9.07 E-05$ & $4.29 E-07$ & -211.3202 & 0.0000 \\
RESID03 & $4.91 E-06$ & $4.25 E-07$ & 11.56329 & 0.0000 \\
RESID04 & $-1.01 E-05$ & $2.77 E-07$ & -36.61985 & 0.0000 \\
RESID05 & $-3.86 E-06$ & $2.67 E-07$ & -14.48333 & 0.0000 \\
X1(-1) & $1.20 E-06$ & $1.57 E-07$ & 7.656616 & 0.0000 \\
X2(-1) & $1.51 E-05$ & $1.62 E-07$ & 93.42363 & 0.0000 \\
X3(-1) & $3.21 E-06$ & $1.56 E-07$ & 20.60031 & 0.0000 \\
X4(-1) & $2.09 E-05$ & $1.56 E-07$ & 134.1565 & 0.0000 \\
X5(-1) & $1.22 E-05$ & $1.62 E-07$ & 75.41072 & 0.0000 \\
\hline R-squared & & & & \\
Adjusted R-squared & 0.999379 & & &
\end{tabular}

Tabela B.2: Regressão do excesso de retorno do yield de 12 meses.

\begin{tabular}{crrrr} 
Variable & Coefficient & Std. Error & t-Statistic & Prob. \\
\hline C & $8.71 E-06$ & $1.62 E-07$ & 53.85655 & 0.0000 \\
RESID01 & -0.000418 & $1.34 E-06$ & -312.2785 & 0.0000 \\
RESID02 & -0.000105 & $4.44 E-07$ & -235.2442 & 0.0000 \\
RESID03 & $-1.05 E-05$ & $4.40 E-07$ & -23.80758 & 0.0000 \\
RESID04 & $-1.48 E-05$ & $2.86 E-07$ & -51.82904 & 0.0000 \\
RESID05 & $4.03 E-06$ & $2.76 E-07$ & 14.60063 & 0.0000 \\
X1(-1) & $5.91 E-06$ & $1.63 E-07$ & 36.39685 & 0.0000 \\
X2(-1) & $1.21 E-05$ & $1.67 E-07$ & 72.42951 & 0.0000 \\
X3(-1) & $7.52 E-06$ & $1.61 E-07$ & 46.59220 & 0.0000 \\
X4(-1) & $2.80 E-05$ & $1.61 E-07$ & 173.8327 & 0.0000 \\
X5(-1) & $1.28 E-05$ & $1.67 E-07$ & 76.38208 & 0.0000 \\
\hline
\end{tabular}

R-squared

0.999744

Adjusted R-squared

0.999721

Tabela B.3: Regressão do excesso de retorno do yield de 18 meses. 


\begin{tabular}{crrrr} 
Variable & Coefficient & Std. Error & t-Statistic & Prob. \\
\hline C & $1.16 E-05$ & $1.25 E-07$ & 93.08603 & 0.0000 \\
RESID01 & -0.000573 & $1.03 E-06$ & -553.7945 & 0.0000 \\
RESID02 & -0.000106 & $3.44 E-07$ & -308.9010 & 0.0000 \\
RESID03 & $-2.69 E-05$ & $3.40 E-07$ & -79.07896 & 0.0000 \\
RESID04 & $-1.16 E-05$ & $2.22 E-07$ & -52.36490 & 0.0000 \\
RESID05 & $9.67 E-06$ & $2.14 E-07$ & 45.25170 & 0.0000 \\
X1(-1) & $1.16 E-05$ & $1.26 E-07$ & 92.52539 & 0.0000 \\
X2(-1) & $5.92 E-06$ & $1.29 E-07$ & 45.80629 & 0.0000 \\
X3(-1) & $1.11 E-05$ & $1.25 E-07$ & 88.89918 & 0.0000 \\
X4(-1) & $3.20 E-05$ & $1.25 E-07$ & 257.1062 & 0.0000 \\
X5(-1) & $1.35 E-05$ & $1.30 E-07$ & 104.0211 & 0.0000 \\
\hline & & & & \\
R-squared & 0.999920 & & & \\
Adjusted R-squared & 0.999913 & & &
\end{tabular}

Tabela B.4: Regressão do excesso de retorno do yield de 24 meses.

\begin{tabular}{crrrr} 
Variable & Coefficient & Std. Error & t-Statistic & Prob. \\
\hline C & $1.63 E-05$ & $3.11 E-07$ & 52.42114 & 0.0000 \\
RESID01 & -0.000852 & $2.57 E-06$ & -331.0783 & 0.0000 \\
RESID02 & $-7.90 E-05$ & $8.56 E-07$ & -92.31035 & 0.0000 \\
RESID03 & $-5.27 E-05$ & $8.47 E-07$ & -62.24814 & 0.0000 \\
RESID04 & $4.71 E-06$ & $5.52 E-07$ & 8.544600 & 0.0000 \\
RESID05 & $8.85 E-06$ & $5.32 E-07$ & 16.63385 & 0.0000 \\
X1(-1) & $2.52 E-05$ & $3.13 E-07$ & 80.57622 & 0.0000 \\
X2(-1) & $-1.41 E-05$ & $3.22 E-07$ & -43.86477 & 0.0000 \\
X3(-1) & $1.46 E-05$ & $3.11 E-07$ & 47.13025 & 0.0000 \\
X4(-1) & $3.50 E-05$ & $3.10 E-07$ & 112.8718 & 0.0000 \\
X5(-1) & $1.53 E-05$ & $3.22 E-07$ & 47.54925 & 0.0000 \\
\hline
\end{tabular}

R-squared

0.999801

Adjusted R-squared

0.999784

Tabela B.5: Regressão do excesso de retorno do yield de 36 meses. 


\begin{tabular}{crrrr} 
Variable & Coefficient & Std. Error & t-Statistic & Prob. \\
\hline C & $1.97 E-05$ & $2.23 E-07$ & 88.02761 & 0.0000 \\
RESID01 & -0.001094 & $1.85 E-06$ & -592.3200 & 0.0000 \\
RESID02 & $-2.12 E-05$ & $6.14 E-07$ & -34.59812 & 0.0000 \\
RESID03 & $-6.14 E-05$ & $6.07 E-07$ & -101.0742 & 0.0000 \\
RESID04 & $1.92 E-05$ & $3.96 E-07$ & 48.52569 & 0.0000 \\
RESID05 & $-6.15 E-07$ & $3.82 E-07$ & -1.611653 & 0.1098 \\
X1(-1) & $4.02 E-05$ & $2.25 E-07$ & 178.9645 & 0.0000 \\
X2(-1) & $-4.24 E-05$ & $2.31 E-07$ & -183.4505 & 0.0000 \\
X3(-1) & $1.35 E-05$ & $2.23 E-07$ & 60.71629 & 0.0000 \\
X4(-1) & $3.53 E-05$ & $2.22 E-07$ & 158.4318 & 0.0000 \\
X5(-1) & $1.65 E-05$ & $2.31 E-07$ & 71.45654 & 0.0000 \\
\hline
\end{tabular}

R-squared

0.999947

Adjusted R-squared

0.999942

Tabela B.6: Regressão do excesso de retorno do yield de 48 meses.

\begin{tabular}{crrrr} 
Variable & Coefficient & Std. Error & t-Statistic & Prob. \\
\hline C & $2.22 E-05$ & $1.36 E-07$ & 163.5509 & 0.0000 \\
RESID01 & -0.001310 & $1.12 E-06$ & -1168.733 & 0.0000 \\
RESID02 & $5.49 E-05$ & $3.72 E-07$ & 147.4612 & 0.0000 \\
RESID03 & $-5.14 E-05$ & $3.68 E-07$ & -139.6381 & 0.0000 \\
RESID04 & $2.49 E-05$ & $2.40 E-07$ & 103.7614 & 0.0000 \\
RESID05 & $-1.00 E-05$ & $2.31 E-07$ & -43.22694 & 0.0000 \\
X1(-1) & $5.53 E-05$ & $1.36 E-07$ & 406.0916 & 0.0000 \\
X2(-1) & $-7.65 E-05$ & $1.40 E-07$ & -545.9473 & 0.0000 \\
X3(-1) & $8.73 E-06$ & $1.35 E-07$ & 64.52246 & 0.0000 \\
X4(-1) & $3.48 E-05$ & $1.35 E-07$ & 258.1736 & 0.0000 \\
X5(-1) & $1.59 E-05$ & $1.40 E-07$ & 112.9702 & 0.0000 \\
\hline
\end{tabular}

R-squared

0.999988

Adjusted R-squared

0.999987

Tabela B.7: Regressão do excesso de retorno do yield de 60 meses. 


\begin{tabular}{crrrr} 
Variable & Coefficient & Std. Error & t-Statistic & Prob. \\
\hline C & $2.61 E-05$ & $3.87 E-07$ & 67.51872 & 0.0000 \\
RESID01 & -0.001698 & $3.20 E-06$ & -530.1757 & 0.0000 \\
RESID02 & 0.000230 & $1.06 E-06$ & 216.1341 & 0.0000 \\
RESID03 & $1.34 E-05$ & $1.05 E-06$ & 12.75684 & 0.0000 \\
RESID04 & $9.77 E-06$ & $6.86 E-07$ & 14.24746 & 0.0000 \\
RESID05 & $-1.29 E-05$ & $6.61 E-07$ & -19.56315 & 0.0000 \\
X1(-1) & $8.41 E-05$ & $3.89 E-07$ & 216.1428 & 0.0000 \\
X2(-1) & -0.000154 & $4.00 E-07$ & -385.7098 & 0.0000 \\
X3(-1) & $-7.91 E-06$ & $3.86 E-07$ & -20.47560 & 0.0000 \\
X4(-1) & $3.39 E-05$ & $3.86 E-07$ & 87.92663 & 0.0000 \\
X5(-1) & $7.23 E-06$ & $4.01 E-07$ & 18.02397 & 0.0000 \\
\hline & & & & \\
R-squared & 0.999957 & & &
\end{tabular}

Tabela B.8: Regressão do excesso de retorno do yield de 84 meses.

\begin{tabular}{crrrr} 
Variable & Coefficient & Std. Error & t-Statistic & Prob. \\
\hline C & $3.21 E-05$ & $9.45 E-07$ & 33.96325 & 0.0000 \\
RESID01 & -0.002236 & $7.81 E-06$ & -286.3600 & 0.0000 \\
RESID02 & 0.000498 & $2.60 E-06$ & 192.0307 & 0.0000 \\
RESID03 & 0.000175 & $2.57 E-06$ & 68.02452 & 0.0000 \\
RESID04 & $-5.29 E-05$ & $1.67 E-06$ & -31.61073 & 0.0000 \\
RESID05 & $2.71 E-05$ & $1.61 E-06$ & 16.82255 & 0.0000 \\
X1(-1) & 0.000124 & $9.49 E-07$ & 130.2573 & 0.0000 \\
X2(-1) & -0.000279 & $9.77 E-07$ & -285.9507 & 0.0000 \\
X3(-1) & $-4.04 E-05$ & $9.43 E-07$ & -42.86268 & 0.0000 \\
X4(-1) & $3.18 E-05$ & $9.41 E-07$ & 33.83506 & 0.0000 \\
X5(-1) & $-2.12 E-05$ & $9.78 E-07$ & -21.65896 & 0.0000 \\
\hline
\end{tabular}

R-squared

0.999887

Adjusted R-squared

0.999877

Tabela B.9: Regressão do excesso de retorno do yield de 120 meses. 